\title{
Is reading ability related to activation dumping speed? Evidence from immediate repetition priming
}

\author{
NACHSHON MEIRAN \\ Tel Aviv University, Tel Aviv, Israel \\ and Rotman Research Institute of Baycrest Centre \\ and University of Toronto, Toronto, Ontario, Canada
}

\begin{abstract}
In parallel processing models, residual activity constitutes noise that must be dumped, and fast dumping is associated with efficient processing. Subjects performed a continuous lexical decision task with repetitions (Experiments 1 and 2). Efficient readers (who had high comprehension and vocabulary scores) showed smaller repetition priming than did inefficient readers, but mostly at Lag 0 (equivalent to 3 -sec stimulus onset asynchrony [SOA]). Experiment 3 manipulated the empty interrepetition interval. It was found that reading ability was negatively related to repetition priming mostly when the SOA was $3 \mathrm{sec}$, but less so when it was 2 or $4 \mathrm{sec}$. Experiment 4 failed to find similar reading ability differences when the task was continuous recognition. The findings are interpreted as showing that efficient readers managed to dump residual activity related to subsemantic information in less than $3 \mathrm{sec}$, whereas inefficient readers required $3-4$ sec.
\end{abstract}

In recent years, there has been an increasing interest in parallel processing (PP) models, a category including both spreading-activation theories (see, e.g., Anderson, 1983; Collins \& Loftus, 1975; Dell, 1986) and parallel distributed processing (PDP; McClelland, Rumelhart, \& the PDP research group, 1986; Rumelhart, McClelland, $\&$ the PDP research group, 1986). These models assume that the cognitive system consists of a network of simple processors that operate in parallel. Although various PP models differ from one another in important respects, they nonetheless share certain assumptions. One assumption of all PP models is that the presentation of a stimulus results in the formation of an activity pattern across a network of highly interconnected units. For example, the identification of the meaning of a word involves activating units associated with the semantic features associated with the word, whereas those not associated remain inactive. ${ }^{1}$ Similarly, the identification of the phonology of a word involves activating units associated with phonological features, and so forth.

Another assumption shared by most PP models is that the processors are mandatorily affected by their input (see, e.g., Neely, 1977; Posner \& Snyder, 1975). ${ }^{2}$ Activity patterns may not vanish immediately when the perceived stimulus is removed or is no longer relevant. In

The preparation of this manuscript was partly supported by the Rotman Research Institute Fellowship. The manuscript is based on N. Meiran's doctoral dissertation, conducted under the supervision of Y. Tsal, whom I wish to thank. I also wish to thank M. Smith, J. Toth, M. Moscovitch, M. Jelicic, and two anonymous reviewers for their comments. Correspondence should be addressed to $\mathrm{N}$. Meiran, Behavioral Sciences, Ben Gurion University, Beer Sheva, Israel 84105 (e-mail: nmeiran@bgumail.bgu.ac.il). these cases some residual activity is present at the time a new stimulus is presented. From the assumptions listed, it follows that residual activity constitutes noise, because it combines with activity generated by the currently perceived stimulus. Furthermore, many PP models assume a hierarchical structure in which processors at higher layers receive their input from processors at lower layers (see, e.g., McClelland \& Rumelhart, 1981). The processors at the higher layers have equal potential to be affected by the signal, resulting from the currently perceived stimulus, and by residual activity, considered as noise. Simulations show that the efficiency with which PP systems "identify" inputs is strongly affected by the presence of residual activity. In general, a network whose processors were initially at rest forms the "correct" activity pattern more quickly and accurately than a network containing residual activity (see, e.g., McClelland \& Rumelhart, 1988). Consequently, it was suggested that PP systems include activation dumping mechanisms which reset the network activity between processing events (McClelland \& Rumelhart, 1988; Ratcliff, Hockley, \& McKoon, 1985; Schneider \& Detwiler, 1987, 1988). For example, Ratcliff et al. wrote, "Although the models ... differ in many respects ... most of the models ... share (or require) some assumption about how activation in the system is dampened down in order to avoid saturation of the system" (p. 436). Therefore, it is reasonable to assume that optimal functioning is associated with efficiency of activation dumping. The focus of the present research was to supply evidence for the psychological reality behind activation dumping.

Reading words is a natural area for the testing of PP assumptions because of the heavy influence of PP models on the psychology of reading (see, e.g., Collins \& Lof- 
tus, 1975; Farah \& McClelland, 1991; Hinton \& Shallice, 1991; McClelland, 1986; McClelland \& Rumelhart, 1981; Posner \& Snyder, 1975; Rumelhart \& McClelland, 1982; Seidenberg \& McClelland, 1989). In the present study, I capitalized on the existing individual differences in high-level measures of reading ability, such as vocabulary and reading comprehension, and on the fact that these measures are correlated with processes at the singleword level (Fredriksen, 1982; Hunt, 1978; Hunt, Lunneborg, \& Lewis, 1975; Jackson, 1980; Jackson \& McClelland, 1975, 1979; Perfetti, 1985). Accordingly, I predicted that, compared with inefficient readers, efficient readers would demonstrate faster activation dumping at the word or subword level. To understand this prediction better, assume that readers are presented with a single letter string at a time. The presentation of the letter string results in the formation of activity patterns in the wordreading system that correspond to visual features, orthography, phonology, and word meaning. At points close in time to the event, both efficient and inefficient readers should show evidence for residual activity associated with the string just presented, since activation dumping would barely have begun. When sufficient time has elapsed, activation dumping will be completed regardless of the subject's reading ability. However, at inbetween intervals, the amount of residual activity should be greater for inefficient than for efficient readers. Therefore, I predicted that at intermediate interrepetition interva's an inverse relation would be found between reading ability and the amount of residual activity. At these intervals, efficient readers should manage to reset the residual activity, whereas inefficient readers should not. ${ }^{3}$

As mentioned, slow activation dumping should lead to failures only if processors are mandatorily affected by their inputs. It is believed that the mandatory effects of inputs result from the acquisition of automaticity (Posner \& Snyder, 1975; Schneider \& Shiffrin, 1977; Shiffrin \& Schneider, 1977). On the basis of these considerations, I decided not to work with beginning readers, for whom reading may not be fully automated. Instead, I worked with high school students, a choice justified by the fact that word-level processes are correlated with high-level reading even among skilled readers (see, e.g., Carpenter \& Just, 1988; Fredriksen, 1982; Hunt, 1978; Perfetti, 1985). Reading ability was assessed by standard tests of reading comprehension, vocabulary, and reading speed. Following Ratcliff et al. (1985), the presence of residual activity was assessed with the continuous speeded lexical decision paradigm with repetitions.

\section{Repetition Priming Effects in Continuous Lexical Decision as Indices of Residual Activity}

In the continuous lexical decision paradigm, subjects are presented with letter stings (typically, hundreds of them), one at a time, and they decide whether or not the strings are real words. Residual activity is implicated by processing facilitation for repeated items. An additional manipulation is the lag between repetitions, usually expressed in terms of the number of intervening items. It is now well established that repetition facilitates performance. Previous research has found repetition priming effects with lexical decision (e.g., Ratcliff et al., 1985), threshold identification (e.g., Feustel, Shiffrin, \& Salsoo, 1983), category decision (Woltz, 1988, 1990), continuous recognition (Ratcliff et al., 1985; Scarborough, Cortese, \& Scarborough, 1977), and so forth. Although the repetition priming effect is facilitatory, it is interpreted as resulting, in part, from residual activity. In fact, repetition priming constitutes an exception to the rule that residual activity disrupts processing. In the case of stimulus repetition, the residual activity and the signal have the same pattern because both result from the same stimulus. Consequently, they amplify one another. However, as I shall argue below, it is only repetition priming at short lags that represents residual activity.

When repetition priming effects are plotted as a function of the interrepetition lag, it is possible to identify several components that differ in duration. In a continuous lexical decision task, repetition priming declines rapidly over the initial interrepetition lag and stabilizes thereafter. Ratcliff et al. (1985) suggested that this pattern results from two "activation components," a short-term component that shows fast decline, and a stable, long-term component. ${ }^{4}$ I suggest (following others, such as Ratcliff et al.) that whereas the immediate repetition priming component reflects residual activity, the long-term component does not. Three major arguments support this conclusion. The first argument refers to the theoretical implications of using the term activation. $\mathrm{PP}$ theories use the term to describe a temporary state of the system. Therefore, activation can account for fast-decaying short- term effects but cannot account for stable long-term effects that last for days or longer (Bentin, 1989; Humphreys, Besner, \& Quinlan, 1988; Ratcliff et al., 1985; Rueckl, 1990). Actually, a subclass of PP models, PDP models, explains the long-term repetition priming effect by changes in the pattern of connectivity between processing units and not by residual activity (see, e.g., Rueckl, 1990).

Second, there is similarity between semantic priming and repetition priming, both of which show a sharp decline over the first few lags (Ashcraft, 1976; Dannebring \& Briand, 1982; Henderson, Wallis, \& Knight, 1984; Kirsner, Smith, Lockhart, King, \& Jain, 1984, Experiment 5; Woltz, 1990). The same is true for phonological priming in unvoweled Hebrew (Bentin, 1989), and for cross-modal priming (Kirsner \& Smith, 1974). These similarities suggest shared underlying mechanisms. Furthermore, semantic priming is explained as resulting in part from residual activity (Collins \& Loftus, 1975; Neely, 1991; Posner \& Snyder, 1975), and a similar explanation can account for phonological and cross-modal priming. It follows that residual activity (semantic, phonological, orthographic, etc.) may underlie immediate repetition priming. I should not be understood as suggesting that semantic and repetition priming are equivalent. They certainly are not (see, e.g., Friedrich, Henik, \& Tzelgov, 1991; Smith, Besner, \& Miyoshi, 1994). To my thinking, the immediate component of repetition prim- 
ing results, in part, from all kinds of temporary activity: orthographic, phonological, and semantic.

My first two arguments were that immediate repetition priming reflects temporary activation. My third argument is that long-term repetition priming reflects other processes. In support, it has been shown that semantic priming and long-term repetition priming have additive effects on reaction time (RT) (Dannebring \& Briand, 1982; Den-Heyer, Goering, \& Dannebring, 1985; Durgunoglu, 1988; Wilding, 1986). Additivity is interpreted as showing that the two manipulations affect different processing stages (Sternberg, 1969). Hence, whereas short-term repetition priming reflects processes similar to those in semantic priming (such as residual activity), the long-term repetition priming does not. This argument is partial because it covers only semantic priming. I am not aware, however, of any studies that have tested similar predictions with regard to other forms of immediate priming effects, such as phonological and orthographic priming.

\section{Experimental Overview and Predictions}

In the experiments, the (Hebrew-speaking) subjects were asked to make speeded lexical decisions. Half the strings were common words, and half were pronounceable nonwords formed by permutations of letter position within words. Stimuli were presented sequentially, with a 3 -sec intertrial interval. Especially stimulus repetitions and interrepetition interval were manipulated. In this respect, my experiments replicate those of Bentin (1989) and Bentin and Moscovitch (1988) in Hebrew and Ratcliff et al. (1985) and Scarborough et al. (1977) for English. The principal measure taken from this task was the size of the repetition priming effect, reflected in the difference in RT between first and second presentations of the letter string. Repetition priming effects were computed separately for each lag. As mentioned above, I predicted a negative correlation between residual activity (indirectly indexed by the immediate repetition priming effect) and reading ability. Furthermore, this prediction was restricted to intermediate interrepetition lags. I could not make an exact prediction regarding the critical lag, and, therefore, included in Experiment 1 four of the five first lags $(0,1,2$, or 4 intervening items between repetitions). The selection of these lag values was based on results from previous studies done with this paradigm (Bentin, 1989; Bentin \& Moscovitch, 1988; Ratcliff et al., 1985; Scarborough et al., 1977), in which most of the initial decline in repetition priming occurred within this range.

As reviewed above, immediate repetition priming is not a pure measure of on-line activation, but a combination of two components: a short-term component reflecting residual activity and a long-term component reflecting other processes. Hence I needed a way to remove the effect of the long-term component on immediate priming. To achieve that goal, I used multiple regression analysis, in which repetition priming effects at each of the lags were the predictors of the reading ability variable.
The standardized regression coefficients ( $\beta$ weights) in the resultant model represent the unique shared variance between repetition priming at the given lag and the reading ability variable. For a given $\beta$ the linear contribution of repetition priming at other lags was statistically removed.

In the continuous lexical decision task in Experiments 1 and 2, the number of intermediate items was used to manipulate the interrepetition interval. In Experiment 3 this interval was manipulated without inserting intervening items. Experiment 4 was similar to Experiment 1 but required recognition responses instead of lexical decisions. Throughout the four experiments, I treated the reading ability variable as continuous rather than using extreme groups, which is less powerful statistically. Consequently, I shall not present means separately computed for efficient and inefficient readers. Rather, all the data will be reported in terms of means and standard deviations computed for the entire group. These statistics will be accompanied by correlations and $\beta \mathrm{s}$. A negative correlation or $\beta$ weight indicates that inefficient readers had larger repetition priming effects than did efficient readers.

\section{GENERAL METHOD}

\section{Reading Ability Tests}

Throughout the four experiments, I used a single score to reflect reading ability. The score was a combination of the two readingrelated subsets from the Intellectual Differential Ability Test Battery (IDAT; Fischman, 1982): Vocabulary and Comprehension. Both subtests were paper-and-pencil tests. Vocabulary was a 40 item, four-choice test in which each item is a Hebrew expression followed by four possible interpretations. Subjects were allowed 10 min on this test. Comprehension ("Follow Instructions") consisted of 40 complex Hebrew instructions that subjects were asked to follow, for example, "How many times does the letter $t$ appear in this sentence?" (In this made-up English example, the correct answer is 7). Subjects were allowed $15 \mathrm{~min}$ on this test. Both internal reliabilities of the two tests are high $(\alpha=.89$; Fischman, 1982). The test-retest reliabilities are acceptable: .80 and .74 for vocabulary and comprehension, respectively (Meiran, 1989). Norms for these tests are based on a representative Israeli sample of 4,000 eighth- and ninth-grade students, half male and half female, all of whom were Israeli born and native speakers of Hebrew (Meiran, 1990).

We combined vocabulary and comprehension scores because they were highly correlated in the normative sample $(r=.68)$. This correlation shows that there is very little reliable variance in each test not shared with the other test. If vocabulary and comprehension were treated as two halves of a single test, the reliability of this test would have been .81 (after boosting with the Spearman-Brown formula). If each of the tests was simply doubled in length, its reliability would have been .94 (the value after boosting the internal reliability). Hence, only $13 \%$ of reliable variance is not shared. Joining the two scores has the benefit of increasing reliability (and statistical power). The joined score (through $z$ scores) of vocabulary and comprehension was labeled verbal ability, a term borrowed from the psychometric literature (see, e.g., Hunt, 1978).

\section{Stimuli}

Most of the words that were used were nouns, but a few were adjectives and verbs. However, in Hebrew, the forms of adjectives and verbs change depending on gender, person, and time. I chose to present verbs and adjectives in the form used in dictionaries: Adjectives were presented in the masculine singular form, and verbs 
were presented as masculine, singular, past tense. Furthermore, Hebrew can be written with or without vowels (see Shimron, 1993 for a recent review). The Hebrew letters supply very little vowel information but supply completely regular consonant information. Vowels are added as diacritical marks (called points) that appear below, above, or inside the letters. However, points are used only in children's books, the Bible, and poetry books. They are seldom used in books read by adults or high school students and are never used in newspapers.

There are two ways in which unpointed Hebrew is written: full writing and missing writing. Missing writing is the canonical form and is almost completely without vowels. In fact, pointing is added to words written in the missing writing system. The full writing system uses two letters, Yod and $V a v$, as vowels. Although these letters can be read as consonants $(Y, V)$, they can also be read as vowels (ee for Yod and $o$ or oo for $V a v$ ). The full writing system is, therefore, partly voweled, despite not using the points. Furthermore, this writing system is now used in most printed materials, such as books and newspapers. For these reasons, I presented all the stimuli using the full writing system. I formed nonwords by permuting letter positions of words having attributes similar to those used intact. All the nonwords were readable.

\section{Apparatus and Stimulus Presentation}

Stimulus presentation and RT measurement were controled by Micro Experimental Laboratory programs (MEL 1.0; Schneider, 1988). All stimuli were presented with text mode that employs the same font as that used by Hebrew word processors. RT measurement was accurate to within $1 \mathrm{msec}$

\section{EXPERIMENT 1}

\section{Method}

\section{Subjects}

The sixty-six 10th-grade students ( 34 females and 32 males) who participated in the experiment reported full mastery of Hebrew. Sixty-two were Israeli born, and 4 of the female subjects immigrated to Israel before the age of 5 years. Hence, all the subjects had the same number of Hebrew schooling years. The subjects received the results of the psychometric tests in return for their participation. Their mean vocabulary score, expressed in normative $z$ scores, was $M_{z}=1.30\left(S D_{z}=0.84\right)$, and their mean comprehension score was $M_{z}=1.34\left(S D_{z}=0.62\right)$. These means reflect that, on the average, the subjects in this sample were above the norm mean (zero) in their verbal ability. The sample standard deviations were accordingly smaller than the normative standard deviation, which is unity.

\section{Stimuli}

The stimuli were 66 words and 66 nonwords. All were two syllables long (3-5 letters). Words were relatively common, with frequency counts (Balgur, 1968) ranging from 10 to 90 per 200,000 . Stimuli were partitioned into 12 lists. Within each list, 2 words and 2 nonwords were repeated. The remaining strings served as fillers. Hence, each list contained 15 trials: 4 repeated items, 2 words, and 2 nonwords (a total of eight trials), and 7 filler items. To form the lists, I sampled both the lag order within each list (e.g., lags could be ordered as $0,4,1,2 ; 4,0,2$, 1 ; etc.) and the order of word (W) and nonword (NW) repetitions for that list (W, W, NW, NW; W, NW, W, NW; W, NW, NW, W; etc.). Twelve of the 24 possible orderings of the four lags were selected randomly. There were 6 possible orders for repeated strings within each list. Each of them was used to order repetitions within 2 lists. Fillers were selected so that the word/nonword ratio was 50:50 on all lags (except for Lag 0 , in which there were no fillers). An additional list served for practice.

\section{Procedure}

The experiment was run in two sessions. The first session consisted of the paper-and-pencil group testing on the vocabulary and comprehension tests, and the second session was devoted to the computerized lexical decision test. Forty subjects were tested individually in the computerized session and 26 subjects were tested in small groups.

\section{Computerized Testing}

Upon entrance to the room, the subject received a short oral description of the test. Detailed instructions were presented by the computer program. Subjects pressed a button to begin the task. Thereafter, the strings were replaced automatically. After a short practice block, the experimental block began, which included 180 trials (repetitions included). The same ordering of trials was used with all the subjects. Each trial consisted of a fixation frame (two lines of equal signs) presented for $1 \mathrm{sec}$ followed by the string presented between the lines for $2 \mathrm{sec}$. In SOA terms, Lag 0 corresponded to $3 \mathrm{sec}$ (the stimulus for $2 \mathrm{sec}$, and the empty frame of the next trial for $1 \mathrm{sec}$ ). Lag 1 corresponds to $6 \mathrm{sec}$, Lag 2 to $9 \mathrm{sec}$, and Lag 4 to $15 \mathrm{sec}$.

The subjects responded with their right-hand index and third fingers. Pressing the "N" key (which served for the Hebrew letter $M e m$, the initial letter of the word Mila, which means word in Hebrew) indicated word, and pressing the neighboring $B$ key indicated nonword. A $200-\mathrm{msec}$ beep of $400 \mathrm{~Hz}$ signaled wrong answers to the 40 subjects tested individually and a $400-\mathrm{msec}$ visual error message served the remaining 26 subjects. Replacing the beep with the visual message was done to prevent interference from neighboring subjects in the group testing. When the session ended, the experimenter thanked the subjects for their participation. The lexical decision session took $10-15 \mathrm{~min}$.

\section{Results}

For Experiments 1-3, I analyzed only RTs that corresponded to repeated stimuli, which received correct responses on both presentations. When verbal ability is not considered, the experimental design could be thought of as having three independent factors: repetition (first vs. second presentation), lag ( $0,1,2$, and 4$)$, and lexical status (word vs. nonword). These factors defined $2 \times 4 \times$ $2=16$ conditions. Median RTs, computed separately for each subject and condition, served as basic data in the remaining analyses.

There were not enough observations per cell to permit comparing words and nonwords within a lag. Therefore, the major analysis was performed after pooling word and nonword data. Nevertheless, separate analyses were also conducted.

\section{Preliminary Analyses}

Comparing words and nonwords. I computed repetition priming scores as RT on the first presentation of the stimulus minus RT on the second presentation. I did this for each lag and separately for words and nonwords. I then entered all these scores as predictors of verbal ability in multiple linear regression and looked into differences in regression weights between words and nonwords separately for each lag. The results indicated a nonsignificant difference between words and nonwords on Lag $0(p=.72)$ and Lag $1(p=.59)$, but a signifi- 
cant difference on Lag $2(p<.01)$ and a marginally significant difference on $\operatorname{Lag} 4(p=.076)$.

Main analysis. To assess the net contribution of the repetition priming effect at each lag to verbal ability, I analyzed the data using multiple regression. In this regression model, verbal ability served as the dependent variable, and the repetition priming scores, each representing a different lag, served as independent factors (Tables 1A-1B).

As reported by other researchers (e.g., Bentin, 1989; Bentin \& Moscovitch, 1988; Ratcliff et al., 1985), the repetition priming effect was much larger at $\operatorname{Lag} 0(M=$ $96 \mathrm{msec}$ ) than at the remaining lags. The correlational and regression analyses showed that, for the pooled data, only immediate repetition effects (Lag 0 ) shared significant unique variance with verbal ability $(\beta=-0.34$, $p<.05)$. The higher the subject's verbal ability score, the lower the repetition priming effect at Lag 0 . However, this was not the case for the remaining lags. The observed difference in regression weights between Lag 0 and the remaining lags was significant $[t(61)=1.70, p<.05$, one-tailed]. Separate analyses of words and nonwords revealed significant $\beta$ weights at Lag 0 . Another marginally significant weight was also found, but for words it was on Lag 4 and had a negative sign, whereas for nonwords it was on Lag 2 and had a positive sign. As argued more fully below, the design did not permit a stable comparison between words and nonwords and, therefore, mainly the pooled data should be considered.

\section{Potential Artifacts}

Speed-accuracy tradeoff. The detailed accuracy data are given in Appendix A. Accuracy was close to ceiling and therefore did not permit statistical analysis. Nevertheless, there was no evidence for a speed-accuracy tradeoff because greater gains in RT were accompanied by greater gains (word data $2 \%$ vs. $1 \%$ for subjects below and above median verbal ability) or smaller losses in accuracy (nonwords: $0 \%$ vs. $1 \%$ loss for subjects below and above median verbal ability).

Scaling. One possible argument might be that negative correlations between repetition priming and verbal ability reflect scaling artifacts (Baron \& Treiman, 1980). That is, inefficient readers are slower than efficient readers in their lexical decisions to the items presented for the first time (baseline). Consequently, they have more room for potential facilitation from priming than do efficient readers, whose RTs in lexical decision are already at floor. However, there is no reason to assume that lag should affect the magnitude of the correlation between verbal ability and RT to the first presentation of the item, and therefore the explanation holds equally well for all lags. The assumption regarding no lag effect on the first presentations was tested and confirmed by an ANOVA that included lag and verbal ability (in its continuous form) as independent factors. The most important test in this nonstandard ANOVA was the interaction, which assessed the heterogeneity of verbal-ability-to-RT slopes across lags. Indeed, higher verbal ability scores were as-

Table 1A

\begin{tabular}{|c|c|c|c|c|c|c|}
\hline & $\begin{array}{r}\text { tistic } \\
\mathbf{P}\end{array}$ & $\begin{array}{l}\text { illiseco } \\
\text { g Verb } \\
\text { rds and }\end{array}$ & $\begin{array}{l}\text { rrela } \\
\text { ty Fro } \\
\text { rds P }\end{array}$ & $\begin{array}{l}\text { nd M } \\
\text { etitio } \\
\text { Expe }\end{array}$ & $\begin{array}{l}\text { Regress } \\
\text { ng for }\end{array}$ & lyses \\
\hline & & RT & $\begin{array}{r}\text { Repe } \\
\text { (P }\end{array}$ & $\begin{array}{l}\text { fects } \\
\text { s) }\end{array}$ & & $\begin{array}{l}\text { lity } \\
\text { nt) }\end{array}$ \\
\hline $\mathrm{Lag}$ & $M$ & $r$ & $\vec{M}$ & $S D$ & $r$ & $\beta$ \\
\hline 0 & 788 & $-.47^{*}$ & $96^{*}$ & 107 & $-.39 *$ & $-.34 *$ \\
\hline 1 & 761 & $-.39 *$ & 23 & 71 & -.19 & -.07 \\
\hline 2 & 762 & $-.43^{*}$ & 0 & 82 & .07 & .08 \\
\hline 4 & 797 & $-48^{*}$ & $49^{*}$ & 91 & $-.24 \dagger$ & -.18 \\
\hline
\end{tabular}

Note-Lags $0,1,2$, and 4 are equivalent to SOAs of 3,6,9, and $15 \mathrm{sec}$. RT, reaction time. ${ }^{*} p<.05$, two-tailed. $\dagger p<.1$, two-tailed.

Table 1B

Simple Statistics (in Milliseconds), Correlations, and Multiple Regression Analyses Predicting Verbal Ability From Repetition Priming for Words (W) and Nonwords (NW) Reported Separately: Experiment 1

\begin{tabular}{|c|c|c|c|c|c|c|c|c|}
\hline \multirow[b]{3}{*}{ Lag } & \multirow{2}{*}{\multicolumn{2}{|c|}{$\frac{\text { Baseline RT }}{M}$}} & \multirow{2}{*}{\multicolumn{2}{|c|}{$\frac{\begin{array}{c}\text { Repetition } \\
\text { Effect }\end{array}}{M}$}} & \multicolumn{4}{|c|}{$\begin{array}{l}\text { Verbal Ability } \\
\text { (Dependent) }\end{array}$} \\
\hline & & & & & \multicolumn{2}{|c|}{$r$} & \multicolumn{2}{|c|}{$\beta$} \\
\hline & W & NW & W & NW & W & NW & W & NW \\
\hline 0 & 735 & 840 & 92 & 101 & $-.34^{*}$ & $-34^{*}$ & $-.31 *$ & $-.31^{*}$ \\
\hline 1 & 699 & 822 & 25 & 21 & .01 & -.12 & -.03 & -.14 \\
\hline 2 & 690 & 837 & -9 & 8 & -.18 & .31 & -.09 & $.23+$ \\
\hline 4 & 691 & 904 & 44 & 53 & $-.23 \dagger$ & -.08 & $-.24 \dagger$ & -.10 \\
\hline
\end{tabular}

Note--Lags $0,1,2$, and 4 are equivalent to SOAs of $3,6,9$, and $15 \mathrm{sec}$. RT, reaction time. ${ }^{*} p<.05$, two-tailed. $\uparrow p<.1$, two-tailed. 
sociated with faster lexical decisions to items presented for the first time, as seen by a significant main effect of verbal ability $[F(1,64)=17.71, r=-.47, p<.0001]$. However, the lag main effect was not significant $[F(3,192)=2.45, p=.065]$, and most importantly, the lag $\times$ verbal ability interaction was far from significant $(F<1)$, indicating that the (linear) relation between verbal ability and RT was constant across lags. In fact, the numerically largest correlation between baseline RT and verbal ability was observed at Lag 4, not at Lag 0 .

Another version of the scaling argument is that when baseline RTs are correlated with verbal ability and the magnitude of the repetition effect is large and reliable, the chances for a significant correlation with verbal ability are highest. However, the separate analyses of words and nonwords showed that at Lag 4, the repetition effect was larger for words than for nonwords, but the trend in correlations was opposite in direction. A much stronger argument against the scaling explanation is the fact that the results were generally replicated in Experiment 2, where the correlations between baseline RTs and verbal ability were small and insignificant.

In an additional attempt to test for scaling artifacts, I computed the correlation between the proportional repetition priming effect (the raw effect divided by the baseline) and verbal ability for Lag 0 . This correlation was significant $(r=-0.30, p<.05)$. Hence, the higher the verbal ability of the subjects, the lower their proportional gain from repetition priming on Lag 0 . A more detailed account of the scaling argument may clarify the importance of the last analysis. The scaling argument holds that, although several component processes are involved in the lexical decision task, inefficient readers perform poorly on all of them relative to efficient readers. It follows that making any of the component processes shorter (by repetition) will benefit inefficient readers more than efficient readers. However, if verbal ability differences were the same for all the underlying component processes, the proportional gain from repetition should not be related to verbal ability. The fact that the proportional gain was related to verbal ability shows that the simple form of the scaling explanation is inappropriate here (see Appendix B for a proof).

\section{EXPERIMENT 2}

In Experiment 1, I found that verbal ability was negatively correlated with repetition priming at the shortest interrepetition lag. At first glance, it might seem that my predictions regarding effects at intermediate lags were not supported. However, as will be shown in Experiment 3, the verbal ability differences in repetition priming were restricted to SOAs of $3 \mathrm{sec}$, which are equivalent to Lag 0 . These differences were not significant when the SOA was shorter $(2 \mathrm{sec})$ or longer than $3 \mathrm{sec}$. Nevertheless, after conducting Experiment 1, I decided to first replicate it. The main differences between Experiments 1 and 2 were that more stimuli were included in each condition and all lag values from 0 through 5 were used. There was also a difference in subjects' ages, since in this experiment I tested 9th- instead of 10th-grade subjects. In Experiment 1 , I made an informal observation that subjects sometimes waited too long before they responded. I therefore instructed subjects in this experiment that the task was easy and that they were not being tested for their knowledge of the word, but rather, for how quickly it took them to identify a familiar word. For this reason, I exeluded relatively infrequent words from the list. Owing to the exclusion of infrequent words and to the limited norms, I had to include filler words that were much more frequent than those used in Experiment 1. It turned out that changing the instructions and word frequency led to a shift in response strategy so that baseline RT was much more weakly related to verbal ability than in Experiment 1.

\section{Method}

\section{Subjects and Procedure}

The subjects were 47 Israeli-born ninth-grade students ( $24 \mathrm{fe}$ males and 23 males) from a vocational high school near Tel Aviv who volunteered to take part in the experiment. Psychometric test results were supplied to the subjects in return for their participation. The sample scores were $M_{z}=0.78\left(S D_{z}=0.86\right)$ and $M_{z}=$ $0.64\left(S D_{z}=0.79\right)$ for vocabulary and comprehension, respectively. Both these means were above the norm mean but were slightly lower than those of the subjects who participated in Experiment 1.

The procedures were identical to those in Experiment 1. One minor difference was the inclusion of a short break in the middle of the computerized testing. All the subjects were tested individually, and the computerized testing took approximately $25 \mathrm{~min}$.

\section{Stimuli}

The words used were quite common as indicated by their frequency counts (Balgur, 1968), which ranged from 22 to 470 per 200,000 . For some filler words, frequency counts were not available, but these words appeared to be in the same frequency range as were the remaining words. Repeated words were in the frequency range of 45 to 100 per 200,000 (median $=57$ per 200,000 ). There were 270 words and 270 nonwords that were partitioned into 20 lists so that each list contained one repetition at each lag. Ten lists had word repetitions on Lags 0,2 , and 4, and nonword repetitions on Lags 1, 3, and 5. The remaining 10 lists contained word repetitions on Lags 1, 3, and 5, and nonword repetitions on Lags 0,2 , and 4 . Ten possible orderings of the six lags were selected. Each ordering served one list in which words were repeated at Lags 0,2 , and 4, and one list in which words were repeated at Lags 1, 3, and 5. Fillers were quasi-randomly assigned with the proviso that the word/nonword ratio was kept at 50:50 for all lags except $\operatorname{Lag} 0$. Furthermore, a list in which words were repeated on Lags 0,2 , and 4 was always followed by a list in which words were repeated on Lags 1, 3, and 5. A similar list served for practice.

\section{Results}

In Experiment 2, I basically replicated the results of Experiment 1. The comparison of words and nonwords was done in the same way as in Experiment 1 . The differences in regression weights between words and nonwords approached significance at Lag 3 ( $p=.054$, twotailed). At Lag 0 , the comparison yielded a $p$ value of .11 . The results of the multiple regression analysis are presented in Tables 2A-2B. 
Table 2A

Simple Statistics (in Milliseconds), Correlations, and Multiple Regression Analyses Predicting Verbal Ability From Repetition Priming for Words and Nonwords Pooled: Experiment 2

\begin{tabular}{|c|c|c|c|c|c|c|}
\hline \multirow[b]{2}{*}{ Lag } & \multicolumn{2}{|c|}{ Baseline RT } & \multicolumn{2}{|c|}{$\begin{array}{l}\text { Repetition Effects } \\
\text { (Predictors) }\end{array}$} & \multicolumn{2}{|c|}{$\begin{array}{l}\text { Verbal Ability } \\
\text { (Dependent) }\end{array}$} \\
\hline & $M$ & $r$ & $M$ & $S D$ & $r$ & $\beta$ \\
\hline 0 & 772 & -.17 & $105^{*}$ & 80 & $-.39 *$ & $-.31^{*}$ \\
\hline 1 & 796 & -.00 & $59^{*}$ & 61 & -.07 & -.00 \\
\hline 2 & 774 & -.09 & $47^{*}$ & 52 & $-.31^{*}$ & -.21 \\
\hline 3 & 777 & -.08 & $21^{*}$ & 70 & -.10 & -.13 \\
\hline 4 & 753 & .01 & 13 & 55 & -.06 & .13 \\
\hline 5 & 775 & -.11 & $35^{*}$ & 68 & $-.39^{*}$ & $-.32^{*}$ \\
\hline
\end{tabular}

Note $-r$ with verbal ability. Lags $0,1,2,3,4$, and 5 are equivalent to SOAs of $3,6,9,12,15$, and $18 \mathrm{sec} . \mathrm{RT}$, reaction time. ${ }^{*} p<.05$, two-tailed. $\dagger p<.1$, two-tailed.

Table 2B

Simple Statistics (in Milliseconds), Correlations, and Multiple Regression Analyses Predicting Verbal Ability From Repetition Priming for Words (W) and Nonwords (NW) Reported Separately: Experiment 2

\begin{tabular}{|c|c|c|c|c|c|c|c|c|}
\hline \multirow[b]{3}{*}{ Lag } & \multirow{2}{*}{\multicolumn{2}{|c|}{$\frac{\text { Baseline RT }}{M}$}} & \multirow{2}{*}{\multicolumn{2}{|c|}{$\frac{\begin{array}{c}\text { Repetition } \\
\text { Effect }\end{array}}{M}$}} & \multicolumn{4}{|c|}{$\begin{array}{l}\text { Verbal Ability } \\
\text { (Dependent) }\end{array}$} \\
\hline & & & & & \multicolumn{2}{|c|}{$r$} & \multicolumn{2}{|c|}{$\beta$} \\
\hline & $W$ & $\mathrm{NW}$ & $\mathrm{W}$ & $\overline{N W}$ & W & NW & W & NW \\
\hline 0 & 731 & 813 & 112 & 98 & $-.43^{*}$ & -.23 & $-.46^{*}$ & -.12 \\
\hline 1 & 740 & $85 \mathrm{I}$ & 64 & 54 & .04 & -.15 & -.05 & -.19 \\
\hline 2 & 719 & 829 & 57 & 38 & $-.25 t$ & -.15 & $-.39^{*}$ & .09 \\
\hline 3 & 696 & 857 & 8 & 35 & $-.30^{*}$ & .09 & -.21 & .17 \\
\hline 4 & 693 & 813 & 10 & 15 & .14 & -.24 & -.01 & $-.33^{*}$ \\
\hline 5 & 699 & 850 & 39 & 30 & -.18 & $-.34 *$ & .02 & $-.43 *$ \\
\hline
\end{tabular}

$18 \mathrm{sec}$. RT, reaction time. ${ }^{*} p<.05$, two-tailed. $t p<.1$, two-tailed.

The means were similar to those reported in Experiment 1 , and showed larger repetition priming effects at Lag $0(M=105 \mathrm{msec})$ than at the remaining lags. The regression analysis also replicated the findings of Experiment 1, with one exception. Unlike in Experiment 1, I found that at Lag 5 , facilitation was as highly related to verbal ability as at Lag 0 . A planned contrast on the regression weights revealed that these two weights (corresponding to Lags 0 and 5) were significantly lower than the weights of the remaining lags $[t(40)=1.85, p<.05]$, one-tailed. It should be recalled that the $\beta$ weight corresponding to Lag 0 was controlled for the linear effect of repetition priming at Lag 5 and vice versa. Hence, the effect that was found at $\operatorname{Lag} 0$ was probably not mediated by the same mechanism as that at Lag 5 . Some aspects of the data suggest (although weakly) the same conclusion. First, at Lag 0 , the $\beta$ weight was significant for words but not for nonwords, whereas the reverse was true for Lag 5 . In addition, the accuracy data (Appendix $C$ ) show that at Lag 0 , inefficient readers benefited more from repetition than did efficient readers. However, at Lag 5, the nonword data (which seem more responsible for verbal ability differences at that lag than word data) show that repetition led to a reduction in response accuracy that was larger for inefficient readers $(4 \%)$ than for efficient readers $(1 \%)$.
Interestingly, despite mean baseline RTs similar to those found in Experiment 1, the correlations between baseline RT and verbal ability were not significant, although five out of six were negative. In addition, the magnitude of the repetition priming effect on intermediate lags was generally larger than in Experiment 1, suggesting that subjects employed different response strategies in the two experiments.

The separate patterns of words and nonwords were noisier than those in Experiment 1, possibly because of the smaller sample size. For this reason, I decided to increase the reliability of the data this time by pooling across experiments instead of pooling words and nonwords within an experiment (Table 3).

As can be seen, increasing the reliability of the data by pooling across experiments resulted in a much cleaner picture than observed for words and nonwords in each experiment separately. These results support the usefulness of my strategy of pooling data and favor the interpretation of most of the fluctuations in the data as reflecting unreliability. What I am suggesting here is not that words and nonwords are the same, but that in order to test their potentially different relationships with lag and verbal ability, one must double, at a minimum, the number of observations per subject (and consequently increase testing time) and test a few hundred subjects. 
Table 3

Joint Analysis of Experiments 1 and 2 (Effect of Experiment Is Partialed Out)

\begin{tabular}{cccccc}
\hline & \multicolumn{2}{c}{ Correlations } & & \multicolumn{2}{c}{$\beta$ weights } \\
\cline { 6 - 6 } \cline { 5 - 6 } Lag & Words & Nonwords & & Words & Nonwords \\
\hline 0 & $-.33^{*}$ & $-.28^{*}$ & & $-.36^{*}$ & $-.23^{*}$ \\
1 & .02 & $-.20^{*}$ & & .02 & -.11 \\
2 & -.12 & .04 & & $-.21^{*}$ & .11 \\
4 & -.08 & -.15 & -.09 & -.11 \\
\hline
\end{tabular}

${ }^{*} p<.05$, two-tailed.

The similar patterns of results for words and nonwords suggested to me that such an effort was unjustified.

Only at Lag 0 did the repetition effects of both words and nonwords correlate significantly with verbal ability. At other lags, the pattern was mixed, but on the average, the tendency was for a negative correlation between verbal ability and repetition priming effect that was small and far from significance. At Lag 2, where word repetition effects showed a significant negative $\beta$ weight, the weight corresponding to nonwords was in the opposite direction.

\section{Potential Artifacts}

Speed-accuracy tradeoff. Detailed results are given in Appendix C. At Lag 0, greater benefits in RT were associated with greater benefits in accuracy, indicating no evidence for a speed-accuracy tradeoff. However, there was a trend in the reverse direction for Lags 2,4 , and 5.

Scaling. An ANOVA of baseline RTs revealed that the main effect of verbal ability was not significant $(F=$ .32 ), and that lag did not significantly interact with verbal ability $(F<1)$. These results suggest that a correlation between baseline RT and verbal ability is not a necessary condition for obtaining a correlation between verbal ability and repetition priming. Furthermore, as before, larger repetition priming effects were not necessarily associated with greater correlations with verbal ability. For example, the repetition priming effect was larger at Lag 1 than at Lag 2, but the correlation was greater at Lag 2 than at Lag 1 . The reader may notice other examples of that sort.

The correlation between verbal ability and the proportional repetition priming effect at Lag 0 was significant ( $r=-0.40, p<.005$, two-tailed). To summarize, despite not showing a significant difference from baseline performance, subjects who differed in verbal ability differed in their absolute and proportional repetition priming effects at Lag 0 .

Taken together, the results indicate that there are two unrelated effects of verbal ability on repetition priming. One effect occurs with relatively distant repetitions (Lag 5 ). This effect possibly reflects verbal ability differences in how stimulus repetition changes the speedaccuracy tradeoff. The other effect, which is the focus of this article, occurs at $\operatorname{Lag} 0$ and does not reflect changes in speed-accuracy tradeoff.

\section{EXPERIMENT 3}

Differences in activation dumping speed should have caused negative correlations between verbal ability and repetition priming at intermediate lags. The results of Experiments 1 and 2 were interpreted as showing that the critical interrepetition delay is around $3 \mathrm{sec}$, equivalent to Lag 0. In Experiment 3, I tested and confirmed this interpretation. In addition, lag and the number of intervening items were perfectly confounded in Experiments 1 and 2 . Therefore, in the present experiment all the repetitions were at Lag 0 , but SOA was manipulated.

While making the necessary procedural changes, I also wished to preserve the task structure, which required that subjects respond to the string also when it was presented for the first time. This requirement implies that SOA could not have been made much shorter than $3 \mathrm{sec}$. Furthermore, SOA could not be made too long, thus causing subjects to lose patience waiting for an item to appear. For these reasons, the SOA values chosen were 2 , 3 (for replication of the Lag 0 effects), and $4 \mathrm{sec}$. My predictions were that the $\beta$ weights, representing the shared variance of verbal ability, and the repetition priming effect would be larger when the SOA was 3 sec than when it was 2 or $4 \mathrm{sec}$. An SOA of $2 \mathrm{sec}$ should not allow the subjects enough time to reset the residual activity, but an SOA of $4 \mathrm{sec}$ should. With an SOA of $3 \mathrm{sec}$, high verbal ability subjects are more likely to complete resetting the residual activity than are low verbal ability subjects. Hence, with that SOA, residual activity (and consequently repetition priming) was predicted to decrease as verbal ability increased.

An additional goal of Experiment 3 was to test the potential extension of Stanovich's (1980) interactive compensatory model to the present findings. As I have argued above, semantic activation may be one component in the immediate repetition priming effect. Furthermore, poor readers show larger semantic priming effects than good readers, although the effect is usually restricted to sentence primes (Briggs, Austin, \& Underwood, 1984; Perfetti, Goldman, \& Hogaboam, 1979; Schwantes, Boesi, \& Ritz, 1980; Simpson, Lorsbach, \& Whitehouse, 1983; Stanovich, West, \& Feeman, 1981; West \& Stanovich, 1978; see also Schvaneveldt, Ackerman, \& Semlear, 1977, who used single-word primes, and Merrill, Sperber, \& McCauley, 1981, who compared sentence and singleword primes). The latter finding was interpreted by Stanovich and his associates as showing an increased use of context among poor readers but not among good readers, to compensate for the formers' inefficient bottom-up processing (Stanovich, 1980; Stanovich, Nathan, West, \& Valla-Rossi, 1985; Stanovich \& West, $1979,1981,1983)$. Consequently, it might be argued that context-based compensation also explains reading ability differences in repetition priming. I wish to emphasize that the argument is not made by Stanovich or by his colleagues, who restrict their claims to semantic priming. Furthermore, such an extension of Stanovich's model to 
the present context is unlikely to be correct because nonwords, which presumably do not have semantics, behaved like words in Experiments 1 and 2. Nevertheless, I decided to apply a direct test of the aforementioned possibility by including associative priming pairs (breadbutter) in Experiment 3. Snow and Neely (1987) have shown that mixing semantic and repetition priming trials resulted in a shrinkage of the semantic priming effect (see also Friedrich et al., 1991). In spite of that, I decided to mix the two conditions, since my point was to show that under the conditions (and subject strategy) in which the present finding was observed, semantic priming did not occur, or if it did, it was unrelated to verbal ability. Either one of these findings would show that the effect found in the previous experiments was not mediated by the compensatory mechanism studied by Stanovich and his associates. A minor goal of the experiment was to generalize the findings by testing subjects' reading speed in addition to verbal ability.

\section{Method}

\section{Subjects}

The subjects were 66 seventh-grade junior high school students, 35 female and 31 male, Israeli born and native Hebrew speakers. All of them came from the same school, located in a satellite town of Tel Aviv. Verbal ability and reading speed results were supplied to subjects through the school counselor in return for their participation. The mean age of the subjects was 13.01 years $(S D=$ 0.43 ). Their mean $z$ scores (based on the eighth- and ninth-grade norms) were $M_{z}=0.29\left(S D_{z}=1.01\right)$ for vocabulary, and $M_{z}=$ $0.39\left(S D_{z}=0.80\right)$ for comprehension. Previous results regarding the IDAT battery showed no significant differences between seventh- and eighth-grade students (Meiran, 1989). Therefore I concluded that the sample was nearly representative of the population in reading ability distribution. It showed mean $z$ scores close to zero and standard deviations close to unity.

\section{Reading Speed Tests}

In this experiment, I added two reading speed tests, sentence verification and word-reading time.

Sentence verification was a paper-and-pencil speeded test. It was composed of two parts, each consisting of 36 simple factual sentences (such as "Bread is made of flour"). The first half included 23 correct and 13 incorrect sentences. The second half included 25 correct and 11 incorrect sentences. On each of the two parts, administered immediately one after the other, $45 \mathrm{sec}$ were allowed. This time limit did not allow subjects to complete the test. In addition, it was assumed that when an item was reached, subjects would respond correctly. Indeed, subjects rarely made any errors on this test. For these reasons, the score I used as an index of reading speed was the number of correct answers across the two halves of the test. The reliability of sentence verification (number correct) was estimated by the split-half Spearman-Brown formula, and was . 75 . The mean sentence verification score was $M=39.6$ (out of $72, S D=10.2$ ).

Word-reading time was a computerized RT test consisting of six, three-sentence paragraphs. After the written instructions, the subject was presented with the texts, word by word, and used the "plus" key on the keypad to replace the words on the screen. Reaction times to each buttonpress were recorded. After reading the paragraph the subjects were to select which of two alternative titles was the most appropriate for that paragraph. These questions were added to motivate reading for comprehension.

The subjects took longer to read the first four words of each paragraph in the word-reading time test than the remaining words in that paragraph (see Gernsbacher, 1991, for a review of similar findings). Therefore, for each paragraph, the median reading time for Words 1-4 and for Word 8 to the last were computed. Principal components analysis conducted on these medians found two eigenvalues greater than 1 . The first component accounted for $63.4 \%$ of the total variance, and the second component explained an additional $10.8 \%$ of that variance. When the two components were extracted and rotated with PROMAX, they did not correspond to first four versus last words, and in fact were uninterpretable. Therefore, a single measure was formed by averaging all the medians (having an internal reliability of $\alpha=.87$ ). This measure reflects the mean time spent reading a single word $(M=609 \mathrm{msec}, S D=178 \mathrm{msec})$. The reading speed score was defined as the mean (through sample $z$ scores) of word-reading time and sentence verification. Before computing the reading speed score, I multiplied the $z$ score of word-reading time by -1 so that the score would reflect how quickly the subject had read the paragraphs and reflect that fast readers would have higher scores than slow readers.

\section{Stimuli}

An improvement in stimulus control was introduced in Experiment 3 . Every related string pair was balanced by a similar control pair, in which the lexical status of the target was opposite: For every word repetition pair, there was a matching pair in which words were followed by nonwords that were composed of the same letters as the words. Therefore, a rough comparison between successive stimuli was uninformative with regard to lexical status. Similarly, for every nonword repetition pair, I added a pair in which the nonword was followed by a similar word. Finally, for every associative priming pair, there was another pair in which the nonword target was formed by permuting the letters of a high associate of the prime word. Another advantage of including these pairs was that subjects could not predict the lexical status of the targets from that of the primes. The stimuli in the control conditions were made of words, nonwords, and associative pairs taken from the same pool as those used in the main prime-target types. As stimuli, 180 letterstring pairs were used, 10 for each condition. The conditions were all the possible combinations of prime-target type and SOA. There were six different prime-target types, which included word repetition, nonword repetition, associative priming, and three control pair types: word followed by a similar nonword, nonword followed by a similar word, and word followed by similar-to-associate nonword. The stimulus pairs within each prime-target type were randomly assigned to SOA. I assigned the stimuli by using a computer program, which was rerun until I obtained near equivalence of stimulus attributes across conditions in terms of mean word frequency, mean priming effect, mean length in syllables, and so forth.

The words used in the word repetition condition were common, as indicated by a mean Balgur (1968) frequency count of 84 per $200,000(S D=53$, range $=35-218)$. Word length in terms of letters was $3-5$, and in syllables, it was $2-3$. Twenty-two words were nouns, 5 were verbs, and 3 were adjectives. Nonword length in syllables was estimated as ranging between two and three syllables. Associative pairs were taken from the semantic priming norms collected by Milman, Tramer, Tzelgov, and Henik (1987) so that prime and target were equal in length in terms of syllables and letters. These lengths were similar to those of the other stimuli used in the experiment. Furthermore, an associative pair was selected only if the norms had shown that it produced a priming effect between 30 and $260 \mathrm{msec}\left(M_{\text {effect }}=109 \mathrm{msec}, S D_{\text {effect }}=49 \mathrm{msec}\right)$. Priming effects were defined as target RT after related prime minus target RT after unrelated prime.

\section{Stimulus Presentation and Procedure}

During the first session, the subjects were tested in groups on the vocabulary, comprehension, and sentence verification tests. Computerized testing was performed during the second session, which was broken into two halves, with each half performed dur- 
ing one lesson period (45 min) and with one lesson period separating the two halves. The first half of that session was devoted to the lexical decision test and the second half to the word-reading time test. Both tests were performed in small groups. Testing on the experiment began with oral and written instructions that explained the task and emphasized both accuracy and speed. The instructions were followed by a short practice session of nine pairs of stimuli, three in each SOA condition. The lexical decision test included a break after 90 pairs. Within each pair, the following sequence of events was used: Two lines of equal signs in the center of the screen for $2 \mathrm{sec}$, the frame with two prewarning exclamation marks for $500 \mathrm{msec}$ (which together made an intertrial interval of $2.5 \mathrm{sec}$ ), the prime within the frame for $1,500 \mathrm{msec}$, an empty frame for a variable interval of $0,1,000$, or $2,000 \mathrm{msec}$, an empty frame with exclamation marks for $500 \mathrm{msec}$, and the target inside the frame for 1,500 msec. Subjects responded to both the prime and the target strings. Therefore, from the subject's perspective, this was a continuous lexical decision experiment, just like Experiments 1 and 2 . A visual error message was presented for $400 \mathrm{msec}$ after erroneous responses. I used the same random order of trials for all the subjects. Subjects responded by pressing the "l" ("word") and "3" ("nonword") keys of the keypad.

\section{Results}

The main regression analyses supported the predictions by showing significant reading ability differences only when the SOA was $3 \mathrm{sec}$ and not when it was 2 or $4 \mathrm{sec}$. In the comparison of words and nonwords, repetition and semantic priming data were analyzed separately.
When I compared the regression weights of words and nonwords, none of the differences reached significance ( $p=.11$ and .55 for SOA of $2 \mathrm{sec}, p=.76$ and .75 for SOA of $3 \mathrm{sec}$, and $p=.08$ and .86 for SOA of $4 \mathrm{sec}$ ). Two sets of analyses were conducted, one with repetition priming and the other with semantic priming. Within each set, two regression models were computed, the first with verbal ability and the second with reading speed as the criterion measures. The results for repetition priming are presented in Tables 4A-4B.

The analyses supported my predictions by showing significant $\beta$ s for SOA of $3 \mathrm{sec}$ and insignificant $\beta \mathrm{s}$ for SOA of 2 and $4 \mathrm{sec}$. The implication is that both verbal ability and reading speed were negatively related to repetition priming but only at an SOA of $3 \mathrm{sec}$. I tested the differences in regression weights for statistical significance by contrasting $3 \mathrm{sec}$ with 2 and $4 \mathrm{sec}$. As predicted, this difference reached statistical significance $[t(62)=$ $1.88,1.94$ for verbal ability and reading speed, both $p s<$ .05 , one-tailed].

Similar analyses were carried out on the semantic priming data. The fact that primes and targets were matched in length, both in terms of letters and in syllables, allowed me to use the prime RT as the baseline for target RT (Table 5).

As can be seen from Table 5, semantic priming was significant when the SOA was 3 or 4 sec. The fact that it

Table 4A

Simple Statistics (in Milliseconds), Correlations, and Multiple Regression Models Predicting Reading Ability From Repetition Priming for Words and Nonwords Pooled: Experiment 3

\begin{tabular}{|c|c|c|c|c|c|c|c|c|}
\hline \multirow{3}{*}{$\begin{array}{l}\text { SOA } \\
(\mathrm{sec})\end{array}$} & \multirow{2}{*}{\multicolumn{2}{|c|}{ Baseline }} & \multirow{2}{*}{\multicolumn{2}{|c|}{$\begin{array}{c}\text { Repetition } \\
\text { Priming Effect } \\
\text { (Predictor) }\end{array}$}} & \multicolumn{4}{|c|}{ Dependent Measure } \\
\hline & & & & & \multicolumn{2}{|c|}{ Verbal Ability } & \multicolumn{2}{|c|}{ Reading Speed } \\
\hline & $M$ & $r$ & $M$ & $\overline{S D}$ & $r$ & $\beta$ & $r$ & $\beta$ \\
\hline 2 & 802 & $\begin{array}{l}\text { VA: }-.43^{*} \\
\text { RS: }-.48^{*}\end{array}$ & $98^{*}$ & 95 & -.01 & .06 & $-.26^{*}$ & -.16 \\
\hline 3 & 830 & $\begin{array}{l}\text { VA: }-.57^{*} \\
\text { RS: }-.52^{*}\end{array}$ & $144^{*}$ & 72 & $-.23 \dagger$ & $-.31 *$ & $-.38^{*}$ & $-.38^{*}$ \\
\hline 4 & 825 & $\begin{array}{l}\text { VA: }-.36^{*} \\
\text { RS: }-.41^{*}\end{array}$ & $119^{*}$ & 74 & -.04 & .10 & -.14 & .10 \\
\hline
\end{tabular}

Note-SOA, stimulus onset asynchrony. $r$ with verbal ability (VA) and reading speed (RS). ${ }^{*} p<.05$, two-tailed. $\dagger p<.1$, two-tailed.

Table 4B

Simple Statistics (in Milliseconds), Correlations, and Multiple Regression Models Predicting Reading Ability From Repetition Priming for Words (W) and Nonwords (NW) Reported Separately: Experiment 3

\begin{tabular}{|c|c|c|c|c|c|c|c|c|c|c|c|c|}
\hline \multirow{4}{*}{$\begin{array}{r}\text { SOA } \\
(\mathrm{sec})\end{array}$} & \multirow{3}{*}{\multicolumn{2}{|c|}{$\frac{\text { Baseline }}{M}$}} & \multirow{3}{*}{\multicolumn{2}{|c|}{$\begin{array}{c}\text { Repetition } \\
\text { Priming Effect } \\
\text { (Predictor) } \\
M\end{array}$}} & \\
\hline & & & & & \multicolumn{8}{|c|}{$\frac{\text { Dependent Measure }}{\text { Reading Speed }}$} \\
\hline & & & & & \multicolumn{2}{|c|}{$r$} & \multicolumn{2}{|c|}{$\beta$} & \multicolumn{2}{|c|}{$r$} & \multicolumn{2}{|c|}{$\beta$} \\
\hline & W & NW & $\bar{W}$ & $\mathrm{NW}$ & W & NW & W & NW & W & NW & W & NW \\
\hline 2 & 706 & 897 & 26 & 171 & .13 & -.12 & .16 & -.05 & -.13 & $-.27^{*}$ & -.07 & -.20 \\
\hline 3 & 735 & 925 & 103 & 185 & -.09 & -.22 & $-.25 \dagger$ & -.17 & -.19 & $-.33^{*}$ & -.17 & $-.29^{*}$ \\
\hline 4 & 728 & 922 & 105 & 133 & .11 & -.16 & .19 & -.08 & -.11 & -.11 & .01 & .05 \\
\hline
\end{tabular}

Note $-r$ with verbal ability and reading speed. SOA, stimulus onset asynchrony. ${ }^{*} p<.05$, two-tailed. $\dagger p<.1$, two-tailed. 
Table 5

Simple Statistics (in Milliseconds), Correlations, and Multiple Regression Models Predicting Reading Ability From Sematic Priming: Experiment 3

\begin{tabular}{|c|c|c|c|c|c|c|c|c|}
\hline \multirow{3}{*}{$\begin{array}{l}\mathrm{SOA} \\
(\mathrm{sec}) \\
\end{array}$} & \multirow{2}{*}{\multicolumn{2}{|c|}{ Baseline }} & \multirow{2}{*}{\multicolumn{2}{|c|}{$\begin{array}{c}\text { Repetition } \\
\text { Priming Effect } \\
\text { (Predictor) } \\
\end{array}$}} & \multicolumn{4}{|c|}{ Dependent Measure } \\
\hline & & & & & \multicolumn{2}{|c|}{ Verbal Ability } & \multicolumn{2}{|c|}{ Reading Speed } \\
\hline & $M$ & $r \dagger$ & $M$ & $S D$ & $r$ & $\beta$ & $r$ & $\beta$ \\
\hline 2 & 720 & $\begin{array}{l}\text { VA: }-.33^{*} \\
\text { RS: }-.37^{*}\end{array}$ & -24 & 114 & .19 & .20 & .01 & .07 \\
\hline 3 & 746 & $\begin{array}{l}\text { VA: }-.43^{*} \\
\text { RS: }-.49^{*}\end{array}$ & $59^{*}$ & 96 & .06 & -.02 & -.17 & -.19 \\
\hline 4 & 743 & $\begin{array}{l}\mathrm{VA}:-.39^{*} \\
\mathrm{RS}:-.28^{*}\end{array}$ & $64^{*}$ & 78 & .01 & .04 & -.03 & .00 \\
\hline
\end{tabular}

${ }^{*} p<.005$, two-tailed. †Correlation with verbal ability (VA) and reading speed (RS).

was not significant when the SOA was 2 sec may be considered a replication of Snow and Neely's (1987) findings. In any case, the pattern of relationships between semantic priming and verbal ability was very different from that observed with repetition priming. No correlation or $\beta$ reached significance. The correlation pattern regarding reading speed was similar to that obtained with repetition priming, showing an insignificant tendency for slower readers to have larger semantic priming effects than fast readers when the SOA was $3 \mathrm{sec}$. The implication of these results is that Stanovich's (1980) interactive compensatory model probably cannot be applied to the present results. These results also support a conceptual replication of Merrill et al.'s study (1981), in which they observed reading ability differences in semantic priming with sentence primes but failed to observe similar differences when single-word primes were used. Nevertheless, it might be the case that the insignificant correlations between semantic priming and the reading ability measures reflect the fact that the semantic priming effect was smaller (and therefore less reliable) than the repetition priming effect.

\section{Potential Artifacts}

Speed-accuracy tradeoff. The correlations with repetition priming were numerically higher for reading speed than for verbal ability. Hence, I tested for speedaccuracy tradeoff by splitting the subjects into two groups according to their median reading speed score (Appendix D). The results showed no evidence for a speed-accuracy tradeoff at any SOA.

Scaling. An ANOVA with SOA and verbal ability as independent factors was run on the baseline RTs. Verbal ability showed a significant main effect $[F(1,64)=21.06$, $p<.0001, r=-.50]$. The main effect of SOA was also significant $[F(2,128)=5.94, p<.005]$, as was the interaction between verbal ability and SOA $[F(2,128)=$ $5.40, p<.01]$. The interaction resulted from the fact that verbal ability was more strongly correlated with lexical decision RT when the SOA was $3 \mathrm{sec}$ than when it was 2 or $4 \sec (r \mathrm{~s}=.42$ and $.36, p s<.005)$. A similar ANOVA was conducted with reading speed instead of verbal ability. Reading speed showed a significant main effect
$[F(1,64)=22.82, p<.0001, r=-.51]$, as did SOA $[F(2,128)=5.75, p<.005]$. However, their interaction was not significant $[F(2,128)=1.68, \mathrm{n} . \mathrm{s}$. $]$. In addition, the correlations between proportional repetition priming scores and verbal ability were not significant $(r \mathrm{~s}=$ $.03,-.09$, and .04 for SOAs of 2,3 , and $4 \mathrm{sec}$, n.s.]. However, when reading speed was used, the correlations were mixed $(r=-.21, p=.083$, for SOA of $2 \mathrm{sec} ; r=-.28$, $p<.05$, for SOA of $3 \mathrm{sec}$; and $r=-.05$, n.s., for SOA of $4 \mathrm{sec}$ ). In conclusion, the analyses suggested that scaling cannot be ruled out as an alternative explanation for the verbal ability results. However, scaling effects do not account adequately for the reading speed data. The reader should bear in mind that the results regarding an SOA of $3 \mathrm{sec}$ and verbal ability were a replication of Experiments 1 and 2 , in which scaling did not pose a major problem. Another argument against the scaling explanation is the fact that the reading ability scores were significantly correlated with baseline RTs in the semantically associated pairs, whereas they were not significantly related to the semantic priming effect. In conclusion, when the results of Experiments 1-3 are considered together, scaling does not seem a viable alternative explanation.

Analysis of fillers for evidence of response activation. As suggested, more than one type of residual activity is conceivable. One type of residual activity may be associated with response generation. I studied response activation by analyzing subjects' RTs to the control pairs (e.g., a word followed by a similar nonword), all of which required the subjects to shift their responses from "word" to "nonword" or the reverse. Activation in the response mechanisms that execute the word responses should retard nonword responses and vice versa. Hence, responses to targets in the control conditions were predicted to be retarded compared with relevant baselines. Furthermore, residual activity should decay over time. Therefore, I predicted that response retardation would decrease as SOA increased. Finally, in order for this function to be interpreted as reflecting response activation, it should be the same regardless of prime-target type. Effects of response activation on reading ability should result in significant interactions involving that variable. The absence of such interactions would suggest 
that reading ability is associated with speed of dumping activation related to word reading and not to response generation. To analyze all the filler conditions within a single ANOVA, I used effect scores rather than raw RTs. At the first stage, I computed the RT difference from the relevant baseline for each subject and condition. The word baseline ( $M=731 \mathrm{msec})$ was computed from mean baselines corresponding to the word repetition and the word-followed-by-nonword conditions. The nonword baseline $(M=911 \mathrm{msec})$ was computed as the mean baseline RTs of nonword repetition and nonwordfollowed-by-word conditions. These effect scores were analyzed by a mixed model, prime-target type $\times$ SOA $\times$ (continuous) verbal ability ANOVA. A similar ANOVA was conducted with reading speed as the subject variable, instead of verbal ability. In addition, I also tested the overall mean if it was significantly different from zero. As predicted, there were no significant effects or interactions involving the reading ability variables, and therefore only the verbal ability ANOVA will be reported. The mean of all scores was significantly larger than zero, showing response retardation on the filler targets $\left[F_{\text {intercept }}(1,64)=85.31, p<.0001\right]$. SOA showed the predicted significant main effect $[F(2,128)=31.91$, $p<.0001]$. An unpredicted main effect of prime-target type was also significant $[F(2,128)=36.41, p<.0001]$. SOA and prime-target type did not interact significantly, as predicted. Figure 1 presents the group means as a function of prime-target type and SOA.

The main effects of SOA and prime-target type were explored by a series of $t$ tests. These tests revealed that the response shift retardation at an SOA of $2 \sec (M=$ $79 \mathrm{msec}$ ) was significantly larger than inhibition at $3 \mathrm{sec}$ $(M=50 \mathrm{msec})$, which, in turn, was significantly larger than inhibition at $4 \mathrm{sec}(M=8 \mathrm{msec}$, both $p \mathrm{~s}<.0001)$. Hence, response-shift retardation declined systematically over SOA, as predicted. Retardation was significantly larger for words after nonwords $(M=90 \mathrm{msec})$ than for nonwords after associated words $(M=36 \mathrm{msec})$, which in turn was significantly larger for nonwords coming after words $(M=10 \mathrm{msec}$, both $p \mathrm{~s}<.005)$.

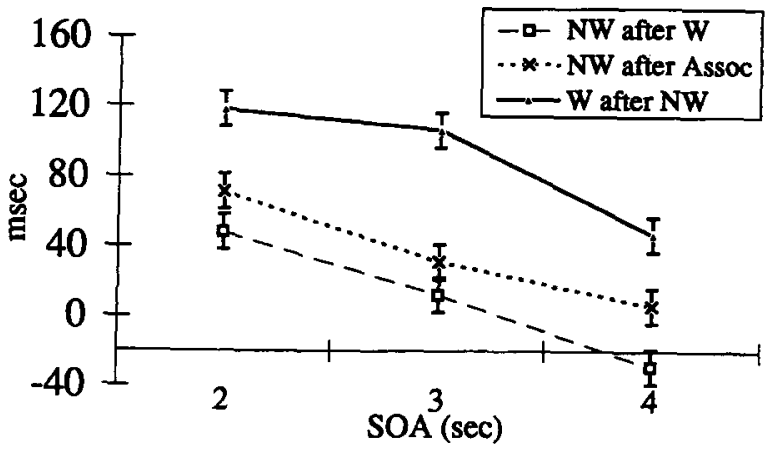

Figure 1: Response-shift inhibition (in milliseconds) as a function of prime-target type and stimulus onset asynchrony: Experiment 3 (see text for details; W, words; NW, nonwords; Assoc., semantic associate).
Each retardation was also tested if it was significantly different from zero. All these tests yielded significant results $(p s<.001)$ except for two: the nonword after similar word, at an SOA of $3 \mathrm{sec}$, and the similar-to-associate nonword at an SOA of $4 \mathrm{sec}$. Note also that responses to nonwords coming after similar words were significantly faster than the baseline at an SOA of 4 sec. $^{5}$

\section{Discussion}

Experiment 3 was a conceptual replication of Experiments 1 and 2, except that SOA was manipulated by the use of an empty interval instead of intervening trials (lag). It revealed a reading ability component in the repetition priming effect that was unique to an SOA of $3 \mathrm{sec}$. According to the activation dumping model, there were no differences in residual activity between efficient and inefficient readers at short SOAs, since none of the subjects had sufficient time to dump the activation, and at long SOAs because all subjects had already dumped the activation. In contrast, at intermediate SOAs, efficient readers managed to dump the activation, whereas inefficient readers did not. Consequently, the immediate repetition effect, which reflects the presence of residual activity in the word-reading system, was larger for inefficient than for efficient readers.

The correlations between immediate repetition priming and verbal ability were smaller than those in Experiments 1 and 2. Nevertheless, Experiment 3 cannot be regarded as a replication failure. To test whether the differences between experiments could be attributed to sampling, I employed meta-analytic procedures (Rosenthal, 1991). One of these procedures allows for focused comparisons between effect sizes (e.g., correlations) computed in different studies. In Experiments 1 and 2, the correlation between repetition priming and verbal ability was $r=-.39$ when the SOA was $3 \mathrm{sec}(\operatorname{Lag} 0)$. The parallel correlation in Experiment 3 was only $r=$ -.23 . However, the values did not differ reliably $(z=$ 0.87 , n.s.). Furthermore, when the same comparison was done against the mean correlation (through Fisher's transformation) corresponding to SOAs of 2 and $4 \mathrm{sec}$, the difference from the $r=-.39$ of Experiments 1 and 2 reached one-sided significance $(z=1.88, p<.05$, onetailed). Finally, the mean correlation between verbal ability and repetition priming, corresponding to SOAs of 2 and $4 \sec (r=-.02)$, did not reliably differ from the mean correlation between verbal ability and repetition priming at Lags $1-5(r=-.19$ and $r=-.19$, for Experiments 1 and 2 , respectively, $z=0.84$, n.s.). In summary, the comparisons showed that the correlations corresponding to an SOA of $3 \mathrm{sec}$ were similar to one another across Experiments 1,2, and 3, and different from the correlations corresponding to other SOAs, which were, in turn, also similar to one another.

In addition to supporting the activation dumping model, the present experiment also rejected other alternative explanations. First, a potential source for immediate repetition priming, other than temporary activa- 
tion, is fast learning (Rueckl, personal communication, 1992). Unlike long-term learning, fast learning (also termed fast-weight learning; see Schneider \& Detwiler, 1987) should result in transient effects. A critical difference between temporary activation and fast learning is the dependence of the latter on intervening activity between repetitions. This assertion is based on the nature of the PDP learning rule (the delta rule) used to simulate slow and fast learning. The delta rule specifies the changes in interunit connections based on the deviation of the actual output from the required output. Hence, for a deltarule-based system to learn, it must generate an output. Experiment 3 established that the elapsed time (during which subjects did not generate outputs), not the number of intervening items, was critical. Hence, fast learning was rejected as a potential mechanism underlying reading ability differences in immediate repetition priming. Finally, although I found evidence for response activation dumping (by analyzing responses to fillers), its rate was not significantly related to reading ability. Therefore, reading ability is related to the speed of activation dumping within some subsystems but not within others, as elaborated in the General Discussion.

One unexpected finding was that the mean repetition priming effect increased when the SOA increased from 2 to $3 \mathrm{sec}$, instead of decreasing, as it should have according to the activation dumping model. That pattern could be explained in a post hoc manner as follows. I suggested that the observed immediate repetition priming effect is composed of two components. It is possible that factors contributing to the long-term component caused a greater increase in the observed effect as opposed to the decreases caused by activation dumping (the short-term component). Consequently, the observed effect showed a small increase. For example, changes in connection strengths that are believed to be responsible for long-term repetition priming (e.g., Rueckl, 1990) may have taken time to build up.

\section{EXPERIMENT 4}

Ratcliff et al. (1985) proposed that a single activation component is responsible for immediate repetition priming in lexical decision and continuous recognition. Related suggestions regarding the role of episodic factors in repeated lexical decisions were made by Feustel et al. (1983; see also Salsoo, Shiffrin, \& Feustel, 1985), by Forster and Davis (1984), and more recently by Bentin and McCarthy (1994). All these considerations might lead to the conclusion that the reading ability differences in repetition priming were due to explicit recognition of the repeated items and not to the on-line activation of the word perception system. It should be noted that adopting this position might imply that inefficient readers have better immediate episodic memory than efficient readers, contrary to what is now accepted (e.g., Daneman \& Carpenter, 1980, 1983).
I chose a straightforward way to test the aforementioned possibility by running a recognition memory experiment that was made as similar as possible to Experiment 1 . The subjects were required to respond "new" on the first presentation of a word and "old" on its second presentation (see Ratcliff et al., 1985; Scarborough et al., 1977). Recognition performance was predicted to decline with lag, thus replicating the findings of Ratcliff et al. and Scarborough et al. According to the episodic memory account, low verbal ability subjects should demonstrate better item memory than high verbal ability subjects at Lag 0 . Unlike in the previous experiments, RTs for first presentations, which required "new" responses, could not serve as baselines, because on repeated presentation they required an "old" response. Hence, most of the analyses were conducted only on the repeated data ("old" responses).

\section{Method \\ Subjects \\ Seventy 10th-grade students ( 37 females and 33 males) partici- pated in this experiment. Sixty-eight subjects were Israeli born na- tive Hebrew speakers and two subjects had come to Israel before the age of 3 years. Hence, all subjects had an equal number of schooling years in Hebrew. Fifty-two of the subjects had partici- pated in Experiment 1 immediately before they were tested on Ex- periment 4 . The sample mean vocabulary score was $M_{z}=1.25$ $\left(S D_{z}=0.78\right)$ and the mean comprehension score was $M_{z}=1.32$ $\left(S D_{z}=0.62\right)$.}

\section{Stimuli}

I used 88 words with attributes similar to those used in Experiment 1 . The words were randomly divided into 11 lists. In each list, 4 words were repeated at Lags $0,1,2$, and 4 . The remaining words served as fillers. Therefore, each list consisted of 15 words. Consequently, there were 10 trials in each lag condition. A similar list served for practice. In addition, every list used a different ordering of lags.

\section{Procedure}

The first session was devoted to the testing on the vocabulary and comprehension tests, and was performed in groups of up to 20 . The second session was devoted to the computerized testing; 44 subjects were tested individually and 26 were tested in small groups. In the individual testing, a $200-\mathrm{msec}$ beep signaled errors, whereas in the group testing, I used a $400-\mathrm{msec}$ visual red message. Oral instructions were given before testing. The computer program began with written instructions, which explained the task and stressed both accuracy and speed. Subjects were run through a short practice session after the instructions and before the experiment. They responded with their right-hand index and third fingers. The "N" key served for "old" responses and the " $B$ " key for "new" responses. Stimulus presentation mode was identical to that used in Experiment 1 .

\section{Results}

Only correct ("old") responses were included in this analysis. As before, the median RTs for each condition (lag) served as basic data for the ANOVA. Lag (repeated measure) and verbal ability (continuous between-subjects effect) served as independent factors. The mean median 
scores were $802,830,842$, and $835 \mathrm{msec}$ for target responses on Lags $0,1,2$, and 4 , respectively.

The higher the verbal ability, the faster were the responses, as indicated by the significant effect of verbal ability $[F(1,68)=7.55, p<.01, r=-.32]$. However, the main effect of lag, despite showing the predicted pattern, was not significant. As predicted, the interaction between lag and verbal ability did not approach significance (both $F \mathrm{~s}<1$ ).

A similar ANOVA was performed on accuracy data, but yielded no significant effects. The mean target accuracies were $0.91,0.94,0.89$, and 0.88 at Lags $0,1,2$, and 4 , respectively. As in the previous analysis, the raw pattern of means agreed with the lag main effect prediction, showing a decline in accuracy over lags.

To give the recognition model a fair chance, I conducted the regression analyses in three different ways. In the first analysis, the predictors were the target RTs; in the second, they were target accuracies; and in the third, they were the RT differences between primes and targets. The only significant effect was found when target RTs served as predictors of verbal ability, showing that the higher the verbal ability score of the subjects, the faster were their recognition RTs at Lag $0(\beta=-.33, p<.05)$. When this weight was compared with the other weights, the difference reached one-tailed significance $[t(65)=1.71, p<$ $.05]$. Two things should be noted. First, the result is not a mere reiteration of the finding regarding verbal ability differences in recognition speed, because it refers to the unique contribution of Lag 0 to this relationship. It should also be noted that the difference found at Lag 0 is exactly in the opposite direction to that observed in the previous experiments. Namely, the higher the verbal ability of the subject, the larger the gain from immediate repetition.

\section{Discussion}

On the basis of the results of Experiment 4, it seems very unlikely that the results of Experiments 1-3 reflected recognition memory. Although the designs of Experiments 1 and 4 were almost identical, the results of these experiments were, if anything, opposite. Whereas Experiment 1 resulted in greater "benefits" from repetition among lower verbal ability subjects than among higher verbal ability subjects, I found some evidence that the opposite may have been true in Experiment 4.

I am not sure why, using a procedure very similar to that used by Hockley (1982), Ratcliff et al. (1985), and Scarborough et al. (1977), I have failed to obtain a significant pattern of RT increases over lags. The insignificant effect does not reflect lack of power, since there was a large number of subjects. Possibly the low memory load, compared with that used in previous studies, was the reason for the discrepant findings. There was no point in increasing the memory load, since our objective was to run an experiment that was as similar as possible to Experiment 1 . The fact that, with similar loads, lag had an effect on continuous lexical decisions but did not have a significant effect on continuous recognition strengthens my ar- gument regarding different underlying mechanisms. My conclusions are in line with the general discrepancy found between direct and indirect measures of memory (see Richardson-Klavehn \& Bjork, 1988; Roediger, 1990; Schacter, 1987; Tulving \& Schacter, 1990; for reviews).

The possibility still remains that subjects adopted different strategies in Experiments 1 and 4, as called for by the different tasks. In Experiment 1, they probably relied mainly on their lexical knowledge, whereas in Experiment 4 they probably relied mainly on their episodic memory. However, inefficient readers may have also relied on their episodic memory while making their lexical decisions (Experiments 1-3), thereby compensating for their deficient lexical access. This possible difference between readers in the tendency to rely on episodic memory could not have been identified in the present experiment, which measured episodic memory ability. However, I still believe this possibility to be unlikely. Given that inefficient readers were as likely to recognize repeated items at Lag 0 and at Lag 1, I do not see why they could not rely on recognition memory on both of these lags. In other words, it does not seem as if the recognition memory explanation can successfully account for the fact that reading ability differences in repetition priming were restricted to an SOA of $3 \mathrm{sec}$.

\section{GENERAL DISCUSSION}

The major finding of the present experiments was that reading ability was inversely related to immediate repetition priming when the SOA was $3 \mathrm{sec}$ but less so when it was shorter $(2 \mathrm{sec})$ or longer (4 sec, or Lags 1-4, which represent SOAs of 6-15 sec). The pattern of results was not as nicely replicated when words and nonwords were treated separately, but this, I believe, reflects the poor reliability more than it reflects true phenomena. In support of this claim, I have shown that pooling data across Experiments 1 and 2 yielded separate results for words and nonwords that were quite similar to those obtained within an experiment when words and nonwords were pooled. In addition, the results of each experiment could be explained as reflecting different artifacts, but when the three first experiments are considered together, most of these problems seem to be solved. For example, scaling could pose a problem in Experiments 1 and 3, in which baseline RT was more strongly correlated with verbal ability than the repetition priming effect. However, in Experiment 2 this pattern was completely reversed, showing very low and insignificant correlations between baseline RT and verbal ability coupled with much larger and significant correlations between repetition priming and verbal ability. I therefore interpret the finding as showing that efficient readers managed to dump residual activity within the word-reading system by less than $3 \mathrm{sec}$, whereas $3-4 \mathrm{sec}$ were required for inefficient readers.

Gernsbacher (1991; Gernsbacher \& Faust, 1991; Gernsbacher, Varner, \& Faust, 1990) explained general comprehension ability by means of a model in which 
suppression of information plays a crucial role. According to her model, comprehenders form an on-line text representation by relating each oncoming proposition to the representation structure that they have previously built (this part of the model is based on Kintsch, 1988). When multiple connotations are implied by an oncoming element, irrelevant ones must be quickly suppressed; otherwise, the comprehender would fail to attach it to the structure. Failing to attach an oncoming element to the structure leads to the formation of a new structure and to the forgetting of the old one. Gernsbacher's model is similar to mine, but refers to a much higher level of analysis than that studied in the present project. Furthermore, in the present project I also measured residual activity associated with relatively high levels of analysis, including semantics and response generation, and did not find significant relationships with reading ability. Taken together, the results suggest that reading ability is related to the speed of dumping activation in system(s) performing low-level analysis of words. Just how low is yet unclear. My experiments were conducted in Hebrew, a language in which cross-case priming is not possible. Hence, I cannot rule out the possibility that the activation that poor readers failed to dump was located at the visual-feature level. However, it cannot be at the very low levels of the retina or even the iconic memory, because an empty fixation frame of at least half a second separated the repetitions. All these considerations suggest that the relevant level at which inefficient readers exhibited slow activation dumping should be subsemantic. Candidates are orthography and sublexical phonology. The fact that words and nonwords behaved quite similarly supports this conclusion: If nonwords were producing diffuse activation patterns in the lexicon, this should have made them similar to words and retard responses instead of facilitating them.

Suppression models of reading ability, like the present one, differ dramatically from theories that attribute reading ability to the degree of automatization of the wordreading processes. For example, Perfetti (1985) based his model on resource theory. According to resource theory (see, e.g., Kahneman, 1973; Navon \& Gopher, 1979), the cognitive system is equipped with limited processing resources that are simultaneously allocated to the different tasks. In addition, resource theories usually assume that the less automatic a process is, the greater is its demand for the limited resources (see, e.g., Navon \& Gopher). According to Perfetti, poor readers fail to fully automatize their word-reading processes. Hence, these processes keep demanding the limited resources. This leaves the poor readers with too little resources for higher level processes, including sentence and discourse comprehension. Hunt and his colleagues (Hunt, 1978; Hunt et al., 1975) identified a specific word-reading process that poor readers fail to automatize: the translation of letter physical codes to letter name codes (see also Jackson, 1980). Another process that poor readers fail to automatize is the ability to employ letter position redundancy in- formation (Fredriksen, 1982; Mason, 1975). I suggest that attributing reading ability only to the degree of automatization rests on the false premise that automatic and skilled performance are synonymous. This is because automatic processing has its costs. It is characterized as uncontrollable (Schneider \& Shiffrin, 1977; Shiffrin \& Schneider, 1977) and as producing outputs that are difficult to ignore (Neely, 1977; Posner \& Snyder, 1975). Accordingly, some authors suggested that the initial stages of skill (reading) acquisition are devoted to the development of automaticity, but that later stages are devoted to the development of its control (e.g., Logan, 1985; Tzelgov, Henik, \& Leiser, 1990). In the present paper, I have pointed out a locus in which automaticity (activation) hurts performance. Furthermore, I have also identified a process that controls automaticity costs (activation dumping) that differentiate between efficient and inefficient readers.

It is unclear how activation is dumped. I could find only three models that describe a specific mechanism of activation dumping. According to McClelland and Rumelhart (1988), "New inputs may need to begin by generating a 'clear signal,' often implemented as a wave of inhibition" (p. 16). In this model, hence, inhibition works as a wave whose action is probably not restricted to the activated portion of the network. In contrast, Schneider and Detwiler (1987) suggested an activation dumping mechanism whose action is restricted to the activated portion of the network. They developed a modular connectionist model, in which

the modules are arranged in levels and regions. Levels represent different processing stages, e.g., visual dots, lines and bars, letters, and words, in which one level feeds information to the next. Each level communicates to the preceding and succeeding levels with two control signals. The LOAD signal between level control structures indicates that the level is transmitting to the succeeding level. The NEXT signal indicates to the preceding level that the signal has been recognized and that the preceding level can reset itself in preparation for additional input from its predecessors. (Schneider \& Detwiler, 1987, pp. 61-62, emphasis added).

Kintsch's (1988) construction-integration model might be called a "restricted" dumping model. According to Kintsch, "The initial activation of lexical knowledge is independent of discourse context. What matters is only the ... associative/semantic context of each word by itself. This stage of sense activation, however, is quickly followed by a process of sense selection in which the discourse context becomes effective: By $500 \mathrm{msec}$, contextinappropriate associates are deactivated" (pp. 171-172, emphasis added). Ferrand and Grainger (1993) described a similar process that operates at lower levels of analysis.

One possibility for discriminating between restricted and unrestricted dumping mechanisms is to look for the pattern of dumping across different priming domains, such as semantic, phonological, orthographic, and so forth. The unrestricted model predicts that activation dumping 
should be synchronized across levels of processing. In the present research, I have found no evidence for reading ability differences corresponding to semantic or responserelated activation dumping. However, I have found reading ability differences in activation dumping associated with sublexical analysis. These facts seem more compatible with a restricted than with an unrestricted activation dumping model. Ferrand and Grainger (1993) have recently reported evidence that seems to favor the restricted dumping model. In their experiment, subjects made lexical decisions to French words preceded by nonword primes that were orthographically similar, phonologically similar, or not similar to the targets. Orthographic priming was maximal when the prime nonwords were presented for $30-50 \mathrm{msec}$ and declined thereafter, during which period phonological priming increased. Presumably, orthographic and phonological priming reflect the activation of the orthographic and the phonological systems. The decline in orthographic priming might reflect a "reset" signal sent to the orthographic system from the phonological system when the latter system was activated.

The restricted model can also explain why words and nonwords have yielded similar results. In the present experiments, subjects probably did not rely heavily on semantic information in making lexical decisions (see Seidenberg \& McClelland, 1989, for a description of a possible mechanism). This was evident in the absence of a semantic priming effect when the SOA was 2 sec. Because semantic information was processed only partly, the semantic system did not signal subsemantic systems to reset their activation. As a consequence, these systems remained active after subjects responded, and their activation was dumped between repetitions. For this reason, reading ability differences in activation dumping were associated mainly with subsemantic information.

One thing that remains unclear is why it took subjects so long to complete activation dumping. I estimated this time to be shorter than $3 \mathrm{sec}$ for efficient readers and longer than $3 \mathrm{sec}$ for inefficient readers--periods long enough to read a short sentence, let alone a single word. I assume that there are at least two activation dumping stages. The first stage is fast, gets rid of most of the residual activation, and is probably based on a mechanism similar to that described by Schneider and Detwiler (1987). This stage must be assumed because most of the activation must be dumped to allow the perception of the next word down the text. The present experiments revealed the operation of a second stage that operates between processing events, that is slow, and that removes whatever is left from the residual activation. Because of its slow rate, the operation of the second mechanism is completed only rarely, because readers are more likely to read the next word down the text before they complete the dumping process. This state of affairs could have led to saturation of the system. Therefore, it is reasonable to assume that the residual activation that is not removed by dumping is eventually cleaned out by interaction between top-down and bottom-up processes (Grossberg \& Stone, 1986) that takes place in reading the next word down the text. This explains why verbal ability differences in repetition priming were found at zero lag only and were not usually found when there were intervening items between repetitions.

In conclusion, I suggest that inefficient readers dump activation in the word-reading system more slowly than efficient readers. As a result, their word-reading systems are noisier than those of efficient readers, require more signal cleanup, and are slow and error prone.

\section{REFERENCES}

ANDERSon, J. R. (1983). The architecture of cognition. Cambridge, MA: Harvard University Press.

AshCRAFT, M. H. (1976). Priming and property dominance in semantic memory. Memory \& Cognition, 4, 490-500.

BALGUR, R. (1968). Reshimat milot yesod lebeit hasefer [A list of elementary words for schools]. Ramat Gan, Israel: Otsar Hamore.

BARON, J., \& Treiman, R. (1980). Some problems in the study of differences in cognitive processes. Memory \& Cognition, 8, 313-321.

BENTIN, S. (1989). Orthography and phonology in lexical decision: Evidence from repetition effects at different lags. Journal of Experimental Psychology: Learning, Memory, \& Cognition, 15, 61-72.

Bentin, S., \& McCarThy, G. (1994). The effects of immediate stimulus repetition on reaction time and event related potentials in tasks of different complexity. Journal of Experimental Psychology: Learning, Memory, \& Cognition, 20, 130-149.

Bentin, S., \& Moscovitch, M. (1988). The time course of repetition effects for words and unfamiliar faces. Journal of Experimental Psychology: General, 117, 148-160.

Briggs, P., Austin, S., \& Underwood, G. (1984). The effects of sentence context in good and poor readers: A test of Stanovich's interactive-compensatory model. Reading Research Quarterly, 20, 54-61.

CARPENTER, P. A., \& JUST, M. A. (1988). The psychology of reading and language comprehension. Boston: Allyn \& Bacon.

Cohen, J. D., Dunbar, K., \& MCClelland, J. L. (1990). On the control of automatic processes: A parallel distributed account of the Stroop effect. Psychological Review, 97, 332-361.

Collins, A. M., \& LofTus, E. F. (1975). A spreading activation theory of semantic processing. Psychological Review, 82, 407-428.

Daneman, M., \& Carpenter, P. A. (1980). Individual differences in working memory and reading. Journal of Verbal Learning \& Verbal Behavior, 19, 450-466.

DANEMAN, M., \& CARPENTER, P. A. (1983). Individual differences in integrating information between and within sentences. Journal of Experimental Psychology: Learning, Memory, \& Cognition, 9, 561-584.

DANNEBRING, G. L., \& BRIAND, K. (1982). Semantic priming and the word repetition effect in a lexical decision task. Canadian Journal of Psychology, 36, 435-444.

DELL, G. S. (1986). A spreading activation theory of retrieval in sentence production. Psychological Review, 93, 283-321.

Den-Heyer, K., Goering, A., \& Dannebring, G. L. (1985). Semantic priming and word repetition: The two effects are additive. Journal of Memory \& Language, 24, 699-716.

DURGUNoǦLu, A. Y. (1988). Repetition, semantic priming, and stimulus quality: Implications for the interactive-compensatory reading model. Journal of Experimental Psychology: Learning, Memory, \& Cognition, 4, 590-603.

FARAH, M. J., \& MCClelland, J. L. (1991). A computational model of semantic memory impairment: Modality specificity and emergent category specificity. Journal of Experimental Psychology: General, 120, 339-357.

Ferrand, L., \& Grainger, J. (1993). The time course of orthographic and phonological code activation in early phases of visual word recognition. Bulletin of the Psychonomic Society, 31, 119-122.

Feustel, T. C., Shiffrin, R. M., \& Salsoo, A. (1983). Episodic and lexical contributions to the repetition effect in word identification. Journal of Experimental Psychology: General, 112, 309-346. 
FISCHMAN, E. (1982). AKA: Ivkhun ksharim intellectualim [IDAT: Intellectual differential aptitude test battery]. Holon, Israel: Hamerkaz Le'Khinukh Technologi.

FoRSTER, K. I., \& DAVIS, C. (1984). Repetition priming and frequency attenuation in lexical access. Journal of Experimental Psychology: Learning, Memory, \& Cognition, 10, 680-698.

FREDRIKSEN, J. R. (1982). A componential theory of reading skills and their interactions. In R. J. Sternberg (Ed.), Advances in the psychology of human intelligence (pp. 125-180). Hillsdale, NJ: Erlbaum.

Friedrich, F. J., Henik, A., \& Tzelgov, J. (1991). Automatic processes in lexical access and spreading activation. Journal of Experimental Psychology: Human Perception \& Performance, 17, 792-806.

Gernsbacher, M. A. (1991). Cognitive processes and mechanisms in language comprehension: The structure building framework. In G. H. Bower (Ed.), The psychology of learning and motivation (Vol. 27, pp. 217-263). New York: Academic Press.

Gernsbacher, M. A., \& Faust, M. E. (1991). The mechanism of suppression: A component of general comprehension skill. Journal of Experimental Psychology: Learning, Memory, \& Cognition, 17, 245262

Gernsbacher, M. A., Varner, K. R., \& Faust, M. E. (1990). Investigating differences in general comprehension skill. Journal of Experimental Psychology: Learning. Memory, \& Cognition, 16, 430-445.

Grossberg, S., \& Stone, G. O. (1986). Neural dynamics of word recognition and recall: Priming, learning, and resonance. Psychological Review, 93, 46-74.

Henderson, L., Wallis, J., \& KNIGHT, D. (1984). Morphemic structure and lexical access. In H. Bauma \& D. G. Bouwhuis (Eds.), At tention and performance $X$ (pp. 211-226). Hillsdale, NJ: Erlbaum.

Hinton, G. E., \& Shallice, T. (1991). Lesioning an attractor network: Investigations of acquired dyslexia. Psychological Review, 98, 74-95.

HoCKLEY, W. E. (1982). Retrieval processes in continuous recognition. Journal of Experimental Psychology: Learning, Memory, \& Cognition, 8, 497-512.

Humphreys, G. W., Besner, D., \& Quinlan, P. T. (1988). Event perception and the word repetition effect. Journal of Experimental Psychology: General, 117, 51-67.

Hunt, E. (1978). Mechanics of verbal ability. Psychological Review, 85, 109-130.

Hunt, E., LunNeborg, C., \& Lewis, A. J. (1975). What does it mean to be high verbal? Cognitive Psychology, 7, 194-227.

JACKSON, M. D. (1980). Further evidence for a relationship between memory access and reading ability. Journal of Verbal Learning \& Verbal Behavior, 19,683-694.

JACKSON, M. D., \& MCCLELLAND, J. L. (1975). Sensory and cognitive determinants of reading speed. Journal of Verbal Learning \& Verbal Behavior, 14, 565-574

JaCkson, M. D., \& MCClelland, J. L. (1979). Processing determinants of reading speed. Journal of Experimental Psychology: General, 108, 151-181.

KaHNEMAN, D. (1973). Attention and effort. Englewood Cliffs, NJ: Prentice-Hall.

KINTSCH, W. (1988). The role of knowledge in discourse comprehension: A construction-integration model. Psychological Review, 95, 163-182.

KIRSNER, K., \& SMITH, M. C. (1974). Modality effects in word identification. Memory \& Cognition, 2, 637-640.

KirSNER, K., SMith, M. C., LOCKHART, R. S., King, M. L., \& JAIN, M (1984). The bilingual lexicon: Language-specific units in an integrated network. Journal of Verbal Learning \& Verbal Behavior, $\mathbf{2 3}$ 519-539.

Logan, G. D. (1985). Executive control in thought and action. Acta Psychologica, 60, 193-210.

Mason, M. (1975). Reading ability and letter search time: Effects of orthographic structure defined by single letter positional frequency. Journal of Experimental Psychology: General, 104, 146-166.

MCCLELland, J. L. (1986). A programmable blackboard model of reading. In J. L. McClelland, D. E. Rumelhart, \& the PDP Research Group (Eds.), Parallel distributed processing: Explorations in the microstructure of cognition (Vol. 2, pp. 122-169). Cambridge, MA: MIT Press, Bradford Books.
McClelland, J. L., \& RumelharT, D. E. (1981). An interactive activation model of context effects in letter perception: Part I. An account of basic findings. Psychological Review, 88, 375-406.

MCCleLland, J. L., \& RumelharT, D. E. (1988). Exploration in parallel distributed processing. Cambridge, MA: MIT Press.

McClelland, J. L., \& Rumelhart, D. E., \& the PDP Research Group. (1986). Parallel distributed processing: Explorations in the microstructure of cognition (Vol. 2). Cambridge, MA: MIT Press, Bradford Books.

MeIRAN, N. (1989). IDAT: Retest reliabilities (Tech. rep.). Holon, Israel: Hamerkaz Le'khinukh Technologi.

Meiran, N. (1990). Age-based norms for IDAT (Tech. rep.) Holon, Israel: Hamerkaz Le'khinukh Technologi.

Merrill, E. C., Sperber, R. D., \& McCauley, C. (1981). Differences in semantic encoding as a function of reading comprehension skill. Memory \& Cognition, 9, 618-624.

Milman, O., Tramer, S., Tzelgov, J., \& Henix, A. (1987). Priming norms for Hebrew words. Beer Sheva, Israel: Ben Gurion University.

MONSELL, S. (1984). Components of working memory underlying verbal skills: A "distributed capacities" view. In H. Bauma \& D. G. Bouwhuis (Eds.), Attention and performance IX (pp. 327-350). Hillsdale, NJ: Erlbaum

Navon, D., \& Gopher, D. (1979). On the economy of the human information processing system. Psychological Review, 86, 214-255.

NEELY, J. H. (1977). Semantic priming and retrieval from lexical memory: Roles of inhibitionless spreading activation and limited capacity attention. Journal of Experimental Psychology: General, 106, 226254.

NeELY, J. H. (1991). Semantic priming effects in visual word recognition: A selective review of current findings and theories. In D. Besner \& G. W. Humphreys (Eds.), Basic processes in reading: Visual word recognition (pp. 264-336). Hillsdale, NJ: Erlbaum.

Perfetti, C. A. (1985). Reading ability. New York: Oxford University Press.

Perfetti, C. A., Goldman, S. R., \& Hogaboam, T. W. (1979). Reading skill and the identification of words in discourse context. Memory \& Cognition, 7, 273-282.

PosNer, M. I., \& SNyder, C. R. R. (1975). Attention and cognitive control. In R. L. Solso (Ed.), Information processing and cognition: The Loyola Symposium. Hillsdale, NJ: Erlbaum.

RATCLIFF, R., HOCKLEY, W., \& MCKOON, G. (1985). Components of activation: Repetition and priming effects in lexical decision and recognition. Journal of Experimental Psychology: General, 114, 435-450.

RichardSON-KLAVEHN, A., \& BJoRK, R. A. (1988). Measures of memory. Annual Review of Psychology, 39, 475-543.

RoEDIGER, H. L. (1990). Implicit memory. American Psychologist, 45, 1043-1056.

ROSENTHAL, R. (1991). Meta-analytic procedures for social research. London: Sage

RUECKL, J. G. (1990). Similarity effects in word and pseudoword repetition priming. Journal of Experimental Psychology: Learning, Memory, \& Cognition, 16, 374-391.

RumelharT, D. E., \& MCClelland, J. L. (1982). An interactive activation model of context effects in letter perception: Part 2 . The contextual enhancement effect and some tests and extensions of the model. Psychological Review, 89, 60-94.

Rumel hart, D. E., MCClelland, J. L., \& The PDP Research Group. (1986). Parallel distributed processing: Explorations in the microstructure of cognition (Vol. 1). Cambridge, MA: MIT Press, Bradford Books

Salsoo, A., Shiffrin, R. M., \& Feustel, T. C. (1985). Building permanent memory codes: Codification and repetition effects in word identification. Journal of Experimental Psychology: General, 114, 50-77.

Scarborough, D. L., Cortese, C., \& Scarborough, H. S. (1977). Frequency and repetition effects in lexical memory. Journal of Experimental Psychology: Human Perception \& Performance, 3, 1-17.

SCHACTER, D. L. (1987). Implicit memory: History and current status. Journal of Experimental Psychology: Learning, Memory, \& Cognition, 13, $501-518$ 
SCHNEIDER, W. (1988). Micro Experimental Laboratory: An integrated system for IBM PC compatibles. Behavior Research Methods, Instruments, \& Computers, 20, 206-217.

SCHNEIDER, W., \& DeTWILer, M. (1987). A connectionist control architecture for working memory. In G. H. Bower (Ed.), The psychology of learning and motivation (Vol. 21, pp. 53-120). New York: Academic Press.

SCHNEIDER, W., \& DETWILER, M. (1988). The role of practice in dual task performance: Toward workload modelling in connectionist/control architecture. Human Factors, 30, 539-566.

Schneider, W., \& Shiffrin, R. (1977). Controlled and automatic human information processing I: Detection, search, and attention Psychological Review, 84, 1-60.

Schvaneveldt, R. W., Ackerman, B. P., \& Semlear, T. (1977). The effects of semantic context on children's word recognition. Child Development, 48, 612-616.

Schwantes, F. M., Boesi, S. L., \& Ritz, E. G. (1980). Children's use of context in word recognition: A psycholinguistic guessing game Child Development, 51, 730-736.

SeidengerG, M. S., \& MCClelland, J. L. (1989). A distributed developmental model of word recognition and naming. Psychological Review, 96, 523-568.

SHIFFRIN, R. (1976). Capacity limitations in information processing, attention, and memory. In W. K. Estes (Ed.), Handbook of learning and cognitive processes (Vol. 4, pp. 177-236). Hillsdale, NJ: Erlbaum.

Shiffrin, R., \& SCHNeIDER, W. (1977). Controlled and automatic human information processing II: Perceptual learning, automatic attending, and a general theory. Psychological Review, 84, 127-190.

Shimron, J. (1993). The role of vowels in reading: A review of studies of English and Hebrew. Psychological Bulletin, 114, 52-67.

Simpson, G. B., Lorsbach, T. C., \& Whitehouse, D. (1983). Encoding and contextual components of word recognition in good and poor readers. Journal of Experimental Child Psychology, 35, 161-171.

Smith, M. C., Besner, D., \& Miyoshi, H. (1994). New limits to automaticity: Context modulates semantic priming. Journal of Experimental Psychology: Learning, Memory, \& Cognition, 20, 104-115.

SNow, N., \& NeEly, J. M. (1987, November). Reduction of semantic priming from inclusion of physically or nominally related prime-target pairs. Paper presented at the annual meeting of the Psychonomic Society, Seattle.

Stanovich, K. E. (1980). Toward an interactive compensatory model of individual differences in the development of reading fluency. Reading Research Quarterly, 16, 32-71.

Stanovich, K. E., Nathan, R. G., West, R., \& Valla-Rossi, M. (1985) Children's word recognition in context: Spreading activation, expectancy, and motivation. Child Development, 56, 1418-1428.

STANOVICH, K. E., \& WEST, R. F. (1979). Mechanisms of sentence context effects in reading: Automatic activation and conscious attention. Memory \& Cognition, 7, 77-85.

Stanovich, K. E., \& West, R. F. (1981). The effect of sentence context on ongoing word recognition: Test of a two process theory. Journal of Experimental Psychology: Human Perception \& Performance, 7. 658-672.

STANOVICH, K. E., \& West, R. F. (1983). On priming by a sentence context. Journal of Experimental Psychology: General, 112, 1-36.

Stanovich, K. E., West, R. F., \& Feeman, D. J. (1981). A longitudinal study of sentence context effects in second grade children: Tests of an interactive compensatory model. Journal of Experimental Child Psychology, 32, 185-199.

STERnBERG, S. (1969). The discovery of processing stages: Extensions of Donder's method. Acta Psychologica, 30, 276-315.

Tulving, E., \& Schacter, D. L. (1990. January). Priming and human memory systems. Science, 247, 301-306.

Tzelgov, J.. Henik, A., \& Leiser, D. ( 1990). Controlling Stroop interference: Evidence from a bilingual task. Journal of Experimental Psuchology: Learning. Memorv, \& Cognition, 16, 760-771.
WEST, R. F., \& STANOVICH, K. E. (1978). Automatic contextual facilitation in readers of three ages. Child Development, 49, 717-727. WILDING, J. (1986). Joint effects of semantic priming and repetition in a lexical decision task: Implications for a model of lexical access. Quarterly Journal of Experimental Psychology, 38A, 213-228.

WOLTZ, D. J. (1988). An investigation of the role of working memory in procedural skill acquisition. Journal of Experimental Psychology: General, 117, 319-331.

Woltz, D. G. (1990). Repetition of semantic comparisons: Temporary and persistent priming effects. Journal of Experimental Psychology: Learning, Memory, \& Cognition, 16, 392-403.

\section{NOTES}

1. The example was given in distributed representation terms (see, e.g., McClelland et al., 1986; Rumelhart et al., 1986). However, the same assumption is made by "local" models in which each processor (network node) stands for a concept (see, e.g., Collins \& Loftus, 1975) or a word (McClelland \& Rumelhart, 1981). In local representation, the formed pattern corresponds to the word/concept node that is activated while all the other nodes are inactive. I also wish to note that the terms active and inactive are relative, meaning "above or below a threshold."

2. Although the citations refer to local semantic memory models, the same conclusion holds for most PDP models and also for local wordreading models like McClelland and Rumelhart's (1981). In both kinds of models, the influence of an input is determined by the strength of the connections between units. Furthermore, most models assume that connection strengths cannot be modified or controlled on line. When the system "learns," connection strengths can be modified, but modification is executed off line when the output that the system has generated is compared with the desired output. Even when on-line control mechanisms are specified in PDP models (see, e.g., Cohen, Dunbar, \& McClelland, 1990; Grossberg \& Stone, 1986), they do not usually involve changes in connection strengths. It follows that on-line input influences within most PDP models are mandatory and not controllable on line.

An additional mechanism for dealing with residual activity was suggested by Schneider and Detwiler (1987). The "gating" mechanism modulates the input to a subsystem by multiplying all the activation values in the input vector by a fraction. Schneider and Detwiler included in their model both gating and dumping (reset) mechanisms. Gating is useful when the input is not needed now but will be needed in the future. However, in most reading tasks, there is no need to store an input that was previously processed, and dumping becomes a more viable alternative.

3. This prediction may seem counterintuitive to some people. One reason is that the term activation was used to account for both on-line processing (as in PP models) and short-term/working-memory phenomena (Shiffrin, 1976, but see also Anderson, 1983; Monsell, 1984; Woltz, 1988). Therefore, I may be understood as suggesting that inefficient readers have better short-term memory than efficient readers, contrary to known facts (see, e.g., Daneman \& Carpenter, 1980). Of course, this is not what I mean. My use of the term activation refers only to on-line processing and never to memory. From this perspective, my predictions are quite intuitive: It is known that high-level reading is correlated with the speed of word-reading processes (see, e.g., Fredriksen, 1982; Hunt, 1978). Therefore, it should also correlate with activation dumping speed.

4. Nonwords and words behave differently, but their repetition priming effects in continuous lexical decisions show a similar decline over the first few lags given, so that subjects respond to the stimuli at both presentations and the stimuli are clearly visible (Bentin, 1989; Bentin \& Moscovitch, 1988; Feustel et al., 1983; Kirsner \& Smith, 1974; Rueck!, 1990; Scarborough et al., 1977). A single exception to this rule is Ratcliff et al.'s (1985) study (Experiment 2), in which only 1 out of 4 subjects showed reliable facilitation. Ratcliff et al.'s study is an exception because it is the only one in which recognition and lexical decision trials were intermixed in the same block. 
5. The unexpected main effect of prime-target type may reflect stimulus activation or learning, which was not affected by SOA within the studied range. Despite being unexpected, this finding should not compromise my conclusions regarding response activation dumping.

\section{APPENDIX A}

Table A

Mean Accuracy According to Response, Lag, and Verbal Ability Group: Experiment 1

\begin{tabular}{|c|c|c|c|c|c|c|c|}
\hline \multirow[b]{2}{*}{ Lag } & \multirow[b]{2}{*}{ Verbal Ability } & \multicolumn{3}{|c|}{ Words } & \multicolumn{3}{|c|}{ Nonwords } \\
\hline & & lst & 2nd & Gain & lst & 2nd & Gain \\
\hline \multirow[t]{2}{*}{0} & low & .98 & 1.00 & .02 & .98 & .98 & .00 \\
\hline & high & .99 & 1.00 & .01 & .98 & .97 & -.01 \\
\hline \multirow[t]{2}{*}{1} & low & .98 & 1.00 & .02 & .94 & .96 & .02 \\
\hline & high & .99 & 1.00 & .01 & .98 & .98 & .00 \\
\hline \multirow[t]{2}{*}{2} & low & .97 &, 99 & .02 & .98 & .99 & .01 \\
\hline & high & .99 & .99 & .00 & .97 & .96 & -.01 \\
\hline \multirow[t]{2}{*}{4} & low & .98 & .99 & .01 & .93 & .93 & .00 \\
\hline & high & .97 & .99 & .02 & .95 & .94 & -.01 \\
\hline
\end{tabular}

Note-Verbal ability groups were formed by a median split.

\section{APPENDIX B}

The purpose of this appendix is to explain why using proportional repetition effects can overcome some problems associated with scaling. Assume for simplicity that the total RT had two additive components (in the sense used by Sternberg, 1969): A and B. The scaling argument, in its simplest form, assumes that to complete any given component, an inefficient reader takes $w(w>1)$ times longer than it takes an efficient reader, with $w$ being a value like 1.4 (meaning that it takes the inefficient reader $40 \%$ longer to complete the process than it takes the efficient reader). If a manipulation would make it unnecessary to go through Process B, its effect on the inefficient reader will be larger $(w \mathrm{~B})$ than its effect on the efficient reader $(\mathrm{B})$. In other words, the efficient reader will "benefit" less from this manipulation than the inefficient reader. However, if the gain had been expressed in terms of proportion, it would have been equal for the two readers. The proportional gain for the efficient reader would be: $B /(A+B)$, and for the inefficient reader, it would be the same: $w \mathrm{~B} /(w \mathrm{~A}+w \mathrm{~B})=w \mathrm{~B} / w(\mathrm{~A}+\mathrm{B})=\mathrm{B} /(\mathrm{A}+\mathrm{B})$.

The analysis of proportional gains safeguards only against the simple version of the scaling explanation. If the assumptions underlying scaling were wrong and the readers differed only on the component that is affected by the manipulation (B), then the inefficient reader would have still benefited more from the manipulation $(w \mathrm{~B} /(\mathrm{A}+w \mathrm{~B})=\mathrm{B} /(\mathrm{A} / w+\mathrm{B}))$ than the efficient reader $(B /(A+B))$.

\section{APPENDIX C}

Table C

Mean Accuracy According to Response, Lag, and Verbal Ability Group: Experiment 2

\begin{tabular}{|c|c|c|c|c|c|c|c|}
\hline \multirow[b]{2}{*}{ Lag } & \multirow[b]{2}{*}{ Verbal Ability } & \multicolumn{3}{|c|}{ Words } & \multicolumn{3}{|c|}{ Nonwords } \\
\hline & & lst & 2nd & Gain & lst & 2nd & Gain \\
\hline \multirow[t]{2}{*}{0} & low & .97 & 1.00 & .03 & .97 & .99 & .02 \\
\hline & high & .98 & .99 & .01 & .97 & .98 & .01 \\
\hline \multirow[t]{2}{*}{1} & low & .96 & .99 & .03 & .97 & .97 & .00 \\
\hline & high & .96 & 1.00 & .04 & .96 & 1.00 & .04 \\
\hline \multirow[t]{2}{*}{2} & low & .97 & .97 & .00 & .97 & .93 & -.04 \\
\hline & high & .98 & 1.00 & .02 & .97 & .95 & -.02 \\
\hline \multirow[t]{2}{*}{3} & low & .92 & .96 & .04 & .94 & .95 & .01 \\
\hline & high & .95 & .97 & .02 & .95 & .95 & .00 \\
\hline \multirow[t]{2}{*}{4} & low & .98 & .98 & .00 & .98 & .97 & -.01 \\
\hline & high & .98 & 1.00 & .02 & .95 & .97 & .02 \\
\hline \multirow[t]{2}{*}{5} & low & .95 & .97 & .02 & .97 & .93 & -.04 \\
\hline & high & .95 & .96 & .01 & .95 & .94 & -.01 \\
\hline
\end{tabular}

Note-Verbal ability groups were formed by a median split.

\section{APPENDIX D}

Table D

Mean Accuracy According to Response, Stimulus Onset Asynchrony (SOA, in Seconds) and Reading Speed Group: Experiment 3

\begin{tabular}{|c|c|c|c|c|c|c|c|}
\hline \multirow[b]{2}{*}{ SOA } & \multirow{2}{*}{$\begin{array}{c}\text { Reading } \\
\text { Speed }\end{array}$} & \multicolumn{3}{|c|}{ Words } & \multicolumn{3}{|c|}{ Nonwords } \\
\hline & & $1 \mathrm{st}$ & 2nd & Gain & 1st & 2nd & Gain \\
\hline \multirow[t]{2}{*}{2} & low & .95 & .92 & -.03 & .83 & .89 & .06 \\
\hline & high & 1.00 & .97 & -.03 & .90 & .91 & .01 \\
\hline \multirow[t]{2}{*}{3} & low & .93 & .97 & .04 & .80 & .94 & .14 \\
\hline & high & .97 & .99 & .02 & .90 & .96 & .06 \\
\hline \multirow[t]{2}{*}{4} & low & .94 & .99 & .05 & .89 & .93 & .04 \\
\hline & high & .96 & .99 & .03 & .92 & .95 & .03 \\
\hline
\end{tabular}

Note-Reading speed groups were formed by a median split.

(Manuscript received December 20, 1994; accepted for publication February 23, 1995.) 